\title{
Gold Nanoparticles: Promising Nanomaterials for the Diagnosis of Cancer and HIV/AIDS
}

\author{
Anil Kumar, ${ }^{1}$ Bhargavi Mazinder Boruah, ${ }^{2}$ and Xing-Jie Liang ${ }^{1}$ \\ ${ }^{1}$ CAS Key Laboratory for Biomedical Effects of Nanoparticles and Nanosafety, National Center for Nanoscience and Nanotechnology, \\ Chinese Academy of Sciences, Beijing 100190, China \\ ${ }^{2}$ CAS Key Laboratory of Pathogenic Microbiology and Immunology, Institute of Microbiology, Chinese Academy of Sciences, \\ Beijing 100101, China \\ Correspondence should be addressed to Xing-Jie Liang, liangxj@nanoctr.cn
}

Received 10 June 2011; Revised 12 August 2011; Accepted 12 August 2011

Academic Editor: Daxiang Cui

Copyright ( $) 2011$ Anil Kumar et al. This is an open access article distributed under the Creative Commons Attribution License, which permits unrestricted use, distribution, and reproduction in any medium, provided the original work is properly cited.

Gold nanoparticles $(A u N P s)$ are currently playing a significant role for human welfare in the field of clinical diagnosis as well as several biomedical applications. More and more research shows that AuNPs-based technologies are becoming promising approaches in cancer research and AIDS treatment. In this paper, we have focused mainly on the exploitation of unique and characteristic properties of $A u \mathrm{NPs}$ such as surface plasmon resonance (SPR), surface enhance Raman scattering (SERS), magnetic properties (MRI), and fluorescence behavior shown upon conjugation with biological and biocompatible ligands. These properties find wide prevalence in biodiagnostics like plasmon-based labeling and imaging, enzyme-linked immunosorbant assay (ELISA), and electrochemical-based methods that can pave the way for developing novel techniques towards diagnosis and therapy of cancer and human immunodeficiency virus/acquired immunodeficiency syndrome (HIV/AIDS).

\section{Why Nanoparticles for Biomedical Applications?}

In contrast to a majority of micro- and macroparticles, nanoparticles (NPs) contain highly significant properties such as molecular fluorophores which make them ideal for biodiagnostic applications. The characteristic properties earmarked for NPs are their (a) small size $(1-100 \mathrm{~nm})$ and correspondingly large surface-to-volume ratio, (b) physical and chemical properties that can be tuned depending upon the requirements of size, composition, and shape (e.g., gold nanoparticles), (c) quantitive and qualitative target-binding properties, and (d) high robustness shown by some of the nanostructure materials [1]. The size of NPs plays an indispensable role in the field of nanobiotechnology which makes them suitable for all biological applications. They offer various advantages over a bulk structure; their characteristic properties make them more ideal. The physical and chemical properties of NPs can have significant effect on the overall function such as target-binding event. In the present research scenario, a number of research and publications are focussing on the tunable physicochemical properties of materials to synthesize highly advanced materials and to boost their robustness. Applications of NPs in biological sciences have a long history as NPs have been used in bioconjugation with peptides, proteins, and DNA and also with some other biological molecules as cellular delivery, labeling, and imaging agents $[2,3]$. Specifically the size, shape, and absorptive and light-scattering properties of some materials exhibit different phenomenon when a beam of light is incident on the surface molecules, which in turn make these materials ideal for multiplexed analyte detection for biological moieties [4-7]. Past few years have seen growth in nanomaterial engineering like the construction of nanowires, nanofibers, and nanotubes which can control the different ways to achieve the target analytes [8]. Additionally, in the present era, methods and techniques for engineering materials such as surface modification, size control, and patterning have reached advances to such a point which now allows generation of very high nanoscale materials for arrays of biomacromolecules and small molecules on surfaces [9-12].

To sum up, engineering the NPs in different directions and ability to tailor the physicochemical properties have 
together given a right way to make the materials more advanced and highly robust for the binding affinities of various biomolecules and drug targets [13-16] as well as for the diagnosis and treatment of diseases like cancer and HIV.

\section{Role of Gold Nanoparticles in Nanobiotechnology}

Gold $(A u)$ is unique compared to other metals because of its resistance to tarnishing. According to the earliest records, use of $A u$ for medical purposes can be traced back to the Chinese civilization in $2500 \mathrm{BC}$, and after that, several ancient cultures have utilized $A u$-based materials for medicinal purpose for the treatment of a variety of diseases such as smallpox, skin ulcers, measles, and syphilis [17]. In today's era of nanotechnology, gold nanoparticles ( $A u$ NPs) have been used for the treatment of diseases like rheumatoid arthritis, and so forth, while considerable research is currently going on for unveiling potential anticancer and antimicrobial and biodiagnostic applications of $A u$-based materials and compounds for clinical applications [18].

In the recent years, nanotechnology has attracted most of the scientific community concerning the applications of nanotechnology in medicine. One particularly exciting field of research involves the use of $A u$ NPs for the diagnosis of cancer. $A u$ NPs find significant exploitations in biomedical field due to (i) their comparative chemical stability, making them less hazardous, (ii) simple and straightforward synthesis and fabrication process, and (iii) genuine biocompatibility and noninterference with other labeled biomaterials (e.g., antibody and other biomarkers) $[15,19]$. Furthermore, the advancement of nanotechnology has led researchers to generate nanostructures that can be conjugated to several kinds of biological molecules, including hormones and antibodies, which can reach targeted cells expressing the receptors [2022]. Colloidal $A u$ has been playing an important role for curing various diseases although the exact mechanism of action is still poorly understood. Today, the applications of $A u$ NPs are increasing day by day in pharmaceutical sciences for human welfare. It can be used to understand more about the nature of diseases like cancer and HIV by providing significant target with nanovehicles [23].

\section{Unique Properties of Gold Nanoparticles for Diagnostic Purpose}

The past two decades have seen rapid changes in the fictionalization of NPs from the point of view of applications such as physiochemical properties, material size, shape, structure morphology, and detailed structural chemistry of the materials [24]. The combination of unique optical, electronic, and magnetic properties exhibited at nanoscale level can be exploited in a systematic manner to design more advanced materials and might be possible to attract the NPs more into the biological field (Figure 1) [1, 4, 25, 26]. Herein, we have reviewed the unique properties of $A u$ NPs which make them the ultimate nanoscale materials for diagnostic purposes.
3.1. Tuning the Optical Properties of Gold for Biodiagnosis. The size-dependent absorbance of $A u$ NPs was explored to demonstrate how alloying affects the chemical stability of NPs and also how composition, size, and nanostructure can be employed to adjust the optical properties [27, 28]. The absorbance and scattering properties of $A u$ NPs can be tuned in accordance with their size parameter [29-32]. NPs less than $20 \mathrm{~nm}$ show only their surface plasma resonance (SPR), but scattering properties of such materials is negligible. In the case of large NPs (20-80 nm), the scattering properties of the materials increase [33]. The spherical $A u$ NPs are colloidal in solution and appear red in color with SPR band positioned at $520 \mathrm{~nm}$ depending upon the size, shape, refractive index of surrounding media, and on the interparticle distance of the NPs (Figure 2) [33-36]. The large $A u$ NPs show relatively high-scattering properties making them more applicable for biomedical applications, whereas those having relatively high-absorption properties are widely used in colorimetric detection of analytes as well as for biological analysis by changing refractive index of $A u$ NP's environment [37]. Similarly, the use of $A g$ - $A u$ alloy-NPs has shown very distinct optical properties and allows for improved detection of biological interactions by novel phenomenon like localized surface plasmon resonance (LSPR) and coupled plasma mass spectrometry (CPMS) [38-40]. LSPR provides an excellent way to improve the sensitivity of plasmon-based bioassays, paving the way for single molecule-based detection and clinically relevant method for diagnostics [40]. Besides detecting biomolecular interaction systems, SPR can also be used to identify interactions involving synthetic receptors like ionophores and imprinted polymers [41]. The use of ionophores as the receptor on the sensor allows the quantitative and specific detection of ionic species molecules [42], while the use of imprinted polymers allows the replacement of antibodies for the quantitative and specific detection of small molecules [43].

3.2. Gold Nanoparticles and Surface Plasmon Resonance $(S P R)$. Surface plasmon resonance (SPR) is a phenomenon occurring at the metal surface when a beam of light is incident on the surface of the molecules at a particular angle and distance (typically in case of gold $(A u)$ and silver $(A g)$ metals or spherical NPs). It is well known that size and thickness of materials play an important role at the metal surface; the SPR phenomenon results in a gradual reduction in intensity of the reflected light. By measuring the appropriate exquisite sensitivity of SPR to the refractive index of the surrounding medium on to the metal surface, it is possible to measure accurately the adsorption and scattering of molecules on the metal surface and their targeted specific ligands [45]. Nowadays, the most common and fundamental application of biosensing SPR instruments is the determination of affinity parameters for biomolecular interactions [45]. The last twenty years have seen tremendous development of SPR and its usage in biomedical applications related to diagnostics and therapy. This technique holds utility not only for measurement in real-time kinetics of ligand-receptor interactions but also in screening of lead compound identification in pharmaceutical drug development as well as in detection of 


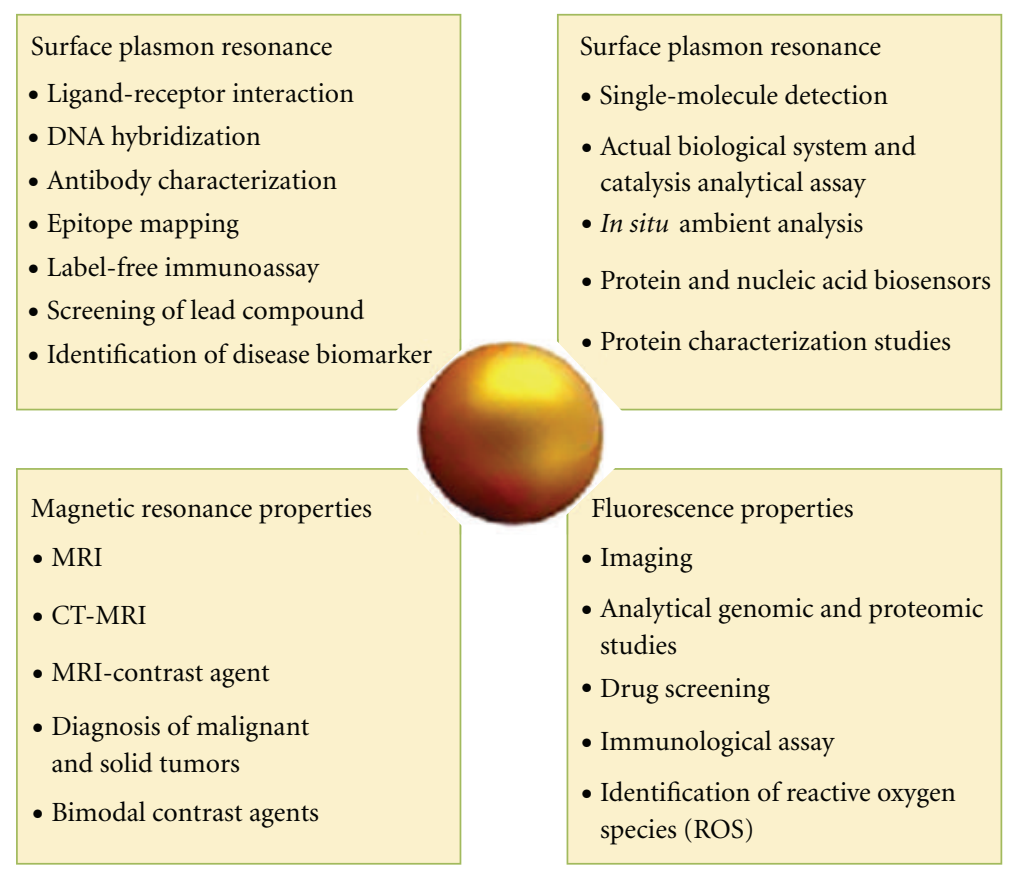

FIgURE 1: Unique properties of $A u$ NPs along with their applications in clinical diagnosis and different biological studies.
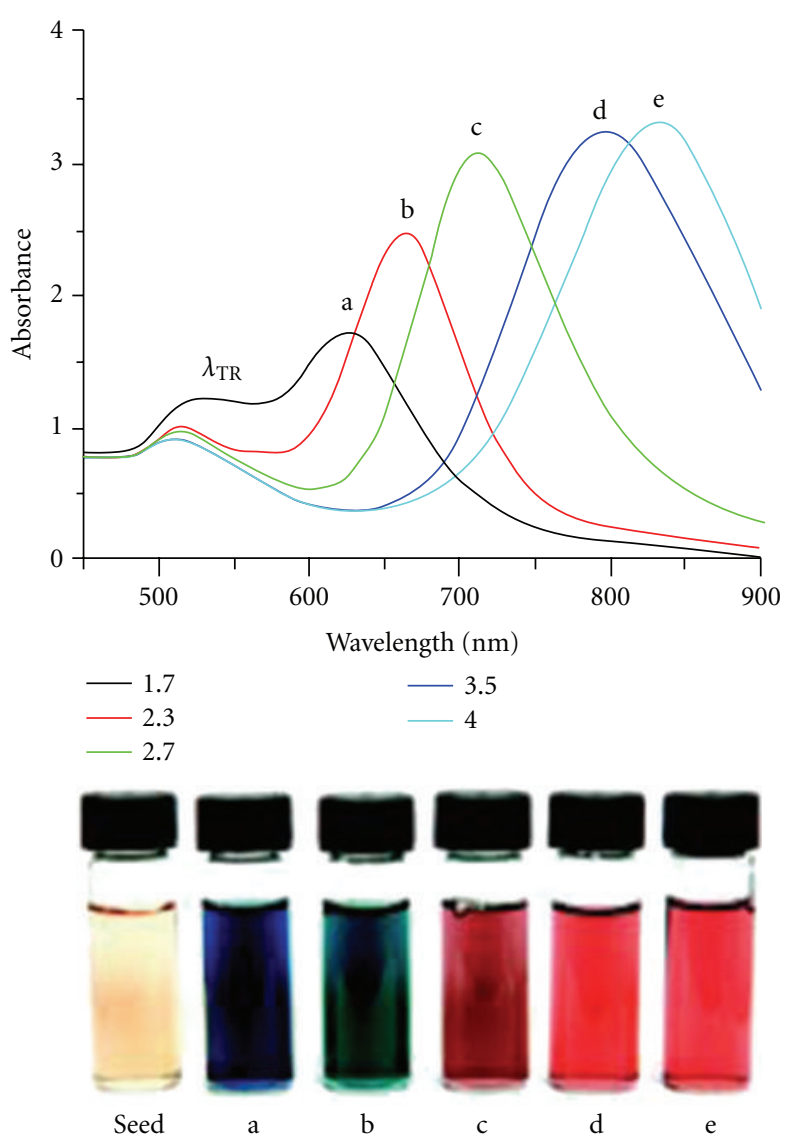

(a)

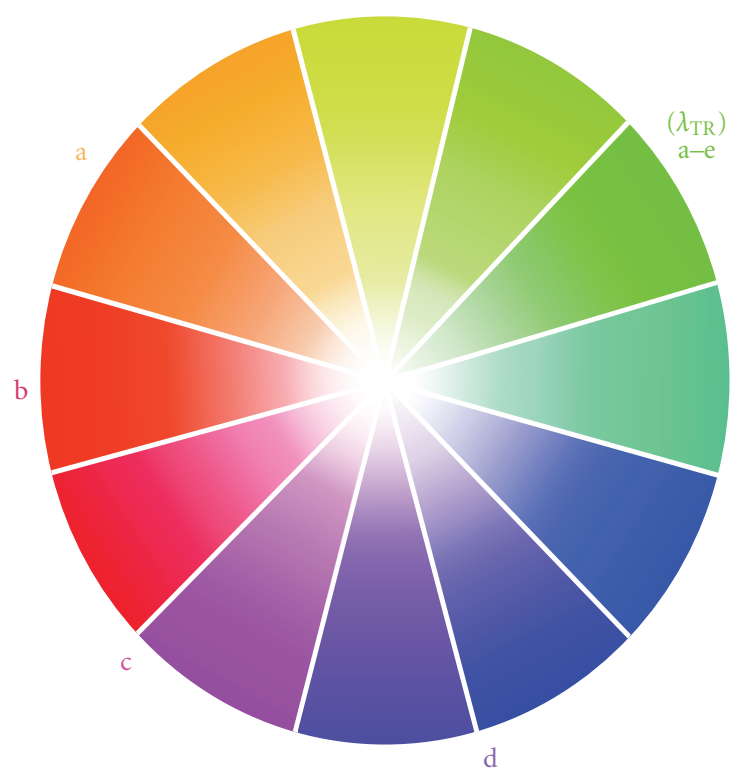

(b)

FIGURE 2: Tunable optical properties of gold nanorods ( $A u$ NRs $)$ with absorptions at visible and near-infrared wavelengths region. (a) Optical absorption spectra of $A u$ NRs with different aspect ratios and composition (a-e). (b) Color wheel representing of $A u$ NRs labeled a-e, TR = transverse resonance. (Reprinted with permission from John Wiley and Sons, [44]). 


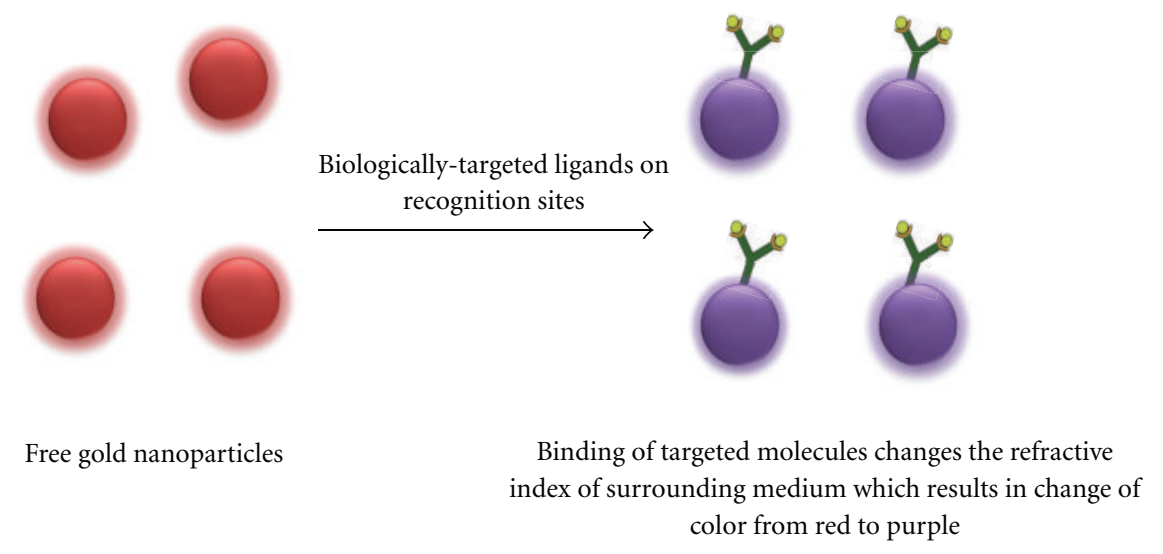

FIGURE 3: SPR phenomenon of $A u$ NPs bound to antibodies or targeted sites leading to color change.

small molecules [46], DNA hybridization [47-50], enzymesubstrate interactions [51], antibody characterization [52, 53], studying antigen-antibody interaction [54-56], characterization of antibody orientations [57], epitope mapping $[58,59]$, protein conformational studies [60], and labelfree immunoassays [61-63]. Boisselier and Astruc [64] have reviewed the significance of the Mie theory and highlighted the fundamentals which depict that the particle morphology such as spherical or nonspherical, various shapes (rods, prisms, triangles, tetrapods, dogbones, cubes, and shells) as well as physical properties of the metal surfaces influences the frequency variation of the plasmon bands. The same phenomenon was observed in the case of $A u$ NPs specially in the case of gold nanorods (AuNRs) [65] which exhibited two plasmon bands, one band corresponding to oscillations along the length of the $A u$ NRs (longitudinal plasmon band) and the other along the width of the $A u$ NRs (transverse plasmon band). $A u$ NRs exhibit plasmon bands at different wavelength-one around 500 and the other at $1600 \mathrm{~nm}$. Thus, it is possible to synthesize $A u$ NRs with suitable ratio, so that they correspond to commercial lasers (e.g., $360 \mathrm{~nm}$, $785 \mathrm{~nm}$, and $1064 \mathrm{~nm}$ ). If the shift of the plasmon band is towards the IR region, $A u$ NRs allow obtaining a penetration into living tissues that is comparatively deeper than visible light with less background fluorescence $[66,67]$. The strong dependence of SPR phenomenon has made $A u$ NRs attractive candidates for colorimetric sensors, photothermal therapy, gene therapy, imaging, and various bioassay applications [65, 68]. $A u$ NPs also change color from red to purple in response to refractive index change in the vicinity of NP surface. Antibodies can be easily attached to the NPs and when the specific analytes bind to the antibodies, the interaction leads to colour changes in proportion to analyte concentration (Figure 3).

3.3. Magnetic Resonance Properties of AuNPs for MRI. The new era of molecular imaging, in vivo characterization, and measurement of biological processes at cellular and molecular level aims at quantifying molecular changes associated with the onset and development of pathological states, thereby, providing early diagnosis and prognosis of diseases like cancer. The imaging of cells, cellular and subcellular structures, requires imaging agents of high relaxivity and density endowed with targeting ability to specific cellular receptors. $A u N P s$ are especially attractive for imaging and therapy due to their SPR, enhanced light scattering, and absorption. In the field of MRI, $A u$ NPs can be used as a template agent in place of Gadolinium $(G d)$ chelates for use as MRI contrast agents due to their high sensitivity $[73,74]$ and also in clinical diagnosis [75, 76]. Cho et al. [77] investigated the coreshell structured iron-gold (Fe-Au) NPs prepared by reverse micelle method, and their potential applications as magnetic resonance (MR) contrast agents. The average NP size is 19 $\mathrm{nm}$, and the materials show high relaxivity and magnetising properties.

Alric et al. [95] reported to have designed $A u$ NPs for MRI where materials exhibit high relaxivity $\left(r=586 \mathrm{nM}^{-1} \mathrm{~s}^{-1}\right.$ as compared to $3.0 \mathrm{nM}^{-1} \mathrm{~s}^{-1}$ for $\mathrm{Gd}$ ), rendering them very attractive as contrast agents for MRI. Another group has reportedly encapsulated $A u$ cores within a multilayered organic shell composed of $G d$ chelates bound to each other through disulfide bonds. The presence of $G d$ ions entrapped in the organic shell results in contrast enhancement, whereas the $A u$ core provides a strong X-ray absorption. The study reveals that these particles are suited for dual modality imaging and circulate freely in the blood vessels without undesirable accumulation in the organ system such as lungs, spleen, and liver. PEG-coated iron oxide gold is a type of core-shell nanoparticles (PEG-AuIONs), measuring approximately $25 \mathrm{~nm}$ in diameter, which reveals high specificity to solid tumors as they accumulate mostly within the tumor mass along with low nonspecific accumulation in the liver and spleen. These results suggest PEG-AuIONs as promising MRI contrast agents for diagnosis of malignant tumors including pancreatic cancer [96]. Nasiruzzaman Sk Md et al. [97] investigated the $A u$ NPs coated by $G d$-chelate (GdL $A u$ ) as a potential CT/MRI Bimodal contrast agent. MRI signaling requires strong magnetic properties of materials for defined use in biodiagnostic purposes.

3.4. Fluorescence Behavior of Gold Nanoparticles. Fluorescence-based assays and detection techniques are among 
the most highly sensitive and popular biological tests in clinical diagnosis. AuNPs show excellent behavior of antiphotobleaching under the presence of strong light illumination. Despite low quantum yields, $A u$ NPs exhibit strong native fluorescence under relatively high excitation energy state. A new fluorescence method has been developed for cell imaging, when the cells stained with $A u N P$ s are illuminated with strong light, the fluorescence of $A u$ NPs on cell membrane or inside cells can be collected for cell imaging [98]. Lee et al. [99] investigated $A u$ nanoprobes immobilized with fluorescein-hyaluronic acid (HA) conjugates which are fabricated and utilized for monitoring intracellular reactive oxygen species (ROS) generation in live cells via NP surface energy transfer. An adhesive molecule, dopamine, is used to robustly end-immobilize HA onto the surface of $A u \mathrm{NPs}$ for securing intracellular stability against glutathione which allows rapid and specific detection of intracellular ROS by emitting strong fluorescence-recovery signals. The result suggests that fluorescent $A u$ nanoprobe is usefully exploited for real-time intracellular ROS detection and antioxidant screening assay and has exciting potential for various biomedical applications as a new class of ROS imaging probes.

Recently, Coto-Garcia et al. [100] reviewed about the $A u$ NPs as fluorescent labels for optical imaging and sensing for analytical genomics and proteomics, with particular emphasis on the outlook for different strategies of using NPs for bioimaging and quantitative bioanalytical applications. Fluorescence resonance energy transfer (FRET) is a spectroscopic technique whereby the excitation energy of the donor electron is transferred to the acceptor via an induced-dipole movement interaction [64]. Depending upon this technique, $A u$ NP-based FRET monitors DNA hybridization, and DNA cleavage by nucleobases after hybridization has been developed by varying the DNA length. The distance between $A u \mathrm{NP}$ and $\mathrm{Cy} 3$ dye was systematically varied between 3 and $100 \mathrm{~nm}$, and 50\% quenching efficiency was observed even at $25 \mathrm{~nm}$ separation [101]. Large molecules such as proteins can be sensed with $20 \mathrm{~nm} A u$ NPs stabilized by Cy5.5-Gly-PoLeu-Gly-Val-Arg-Gly-Cys-(amide) showing selectivity for a matrix metalloprotease served as fluorescent imaging probe for in vivo drug screening and protease activity [102]. You et al. [103] reported the use of a fluorescent polymer to decode the response produced by nanomolar concentrations of proteins by selective $A u \mathrm{NP}$-protein affinities. Other groups employed $A u \mathrm{NPs}$ as fluorescence quenchers for the detection of the protein cardiac troponin [ $\mathrm{T}(\mathrm{cTnT})]$ by its simultaneous interaction with two different antibodies, one attached to $A u \mathrm{NP}$ and the other labeled with fluorescent dyes [104].

\section{Current Clinical Diagnosis Using Gold Nanoparticles}

Diagnosis and treatment of cancer in nascent stages are of great importance because of the widespread occurrence of the disease, high death rate, and the frequency of reoccurrence even after treatment. According to cancer statistics 2010 done by American Cancer Society, estimated new cancer cases were 1,529,560 and 569,490 death in both males and females in the US [105]. However, the exact survival rate of cancer patients is heavily dependent on early diagnosis [106]. Hence, developing technologies applicable for the sensitivity detection of cancer at the initial stages has always been one of the most pressing issues in diagnosis [107]. Diagnostics is an area where nanotechnology, particularly using $A u$, has the ability to revolutionize the way of dealing with the disease. $A u$-based NPs are the perfect raw materials for robust, rapid diagnostic testing to detect cancer and HIV. The minute quantities required make it inexpensive, whilst its stability, sensitivity, and reproducibility as well as highquality supplies give manufacture guarantee due to which it is already commercially available. The unique properties of $A u N P s$ offer various advantages which are currently being studied in exciting fields of academic research due to which potential products are now heading towards the market. However, current methods of cancer diagnosis and treatment are costly and can have adverse side effects to the body organs. $A u \mathrm{NPs}$ offer an inexpensive and significant route to targeting only cancerous cells, leaving healthy cells untouched without doing any harm [108]. The unique light absorption and emission and scattering properties of $A u$ NPs have made them the most studied entities during recent years in cancer diagnostics [108]. Biomarkers related to cancer cells and optical contrast agents provide excellent signal sources from cancer tissues to detect them from complex environment. Most of the larger $A u N P s$ make them promising probes for cancer detection based on imaging because of their scattering properties. Cancer cells are targeted with antibody $A u$ NPs by selectively binding antigens. For example, cervical epithelial cancer cells ( $\mathrm{SiHa}$ cells) that overexpress the transmembrane glycoprotein and epithelial growth factor receptor (EGFR) were imaged by immunotargeted $A u$ NPs for the early stage of prostate cancer detection [78]. Biomarkers have been employed for the early cancer screening and diagnosis $[109,110]$. The recent major developments in the diagnosis of cancer are summarized in Table 1. However, low concentrations of these biomarkers in the complex environment lose their effects often making it difficult to detect the specificity and target. Baptista et al. [111] have demonstrated three approaches for diagnosis of cancer based on $A u \mathrm{NPs}$, namely, (i) colorimetric sensing for specific DNA hybridization, depending upon inter- $A u \mathrm{NP}$ distance for the detection of specific nucleic acid sequences in biological samples, (ii) surface functionalization with different coating materials resulting in highly selective nanoprobes, and (iii) electrochemical-based methods for signal enhancement detection. On the basis of these three methods, clinical diagnosis has been emphasized to applications of cancer and HIV/AIDS using $A u$ NPs.

4.1. Bioconjugation on AuNPs Surface for Diagnosis of Cancer. $A u$ NPs make promising probes for cancer detection based on immunotargeting of antibody- $A u$ NP-labelled cancer cells. $\mathrm{SiHa}$ cells, a type of cancer cell line, overexpressing the transmembrane glycoprotein, epithelial growth factor receptor (EGFR), can be imaged by immunotargeted $A u$ NPs in case of pericervical cancer [78]. AuNPs can be modified with PEG and covalently conjugated with monoclonal antibody (MAb), Herceptin (HER), that enables recognition of breast 


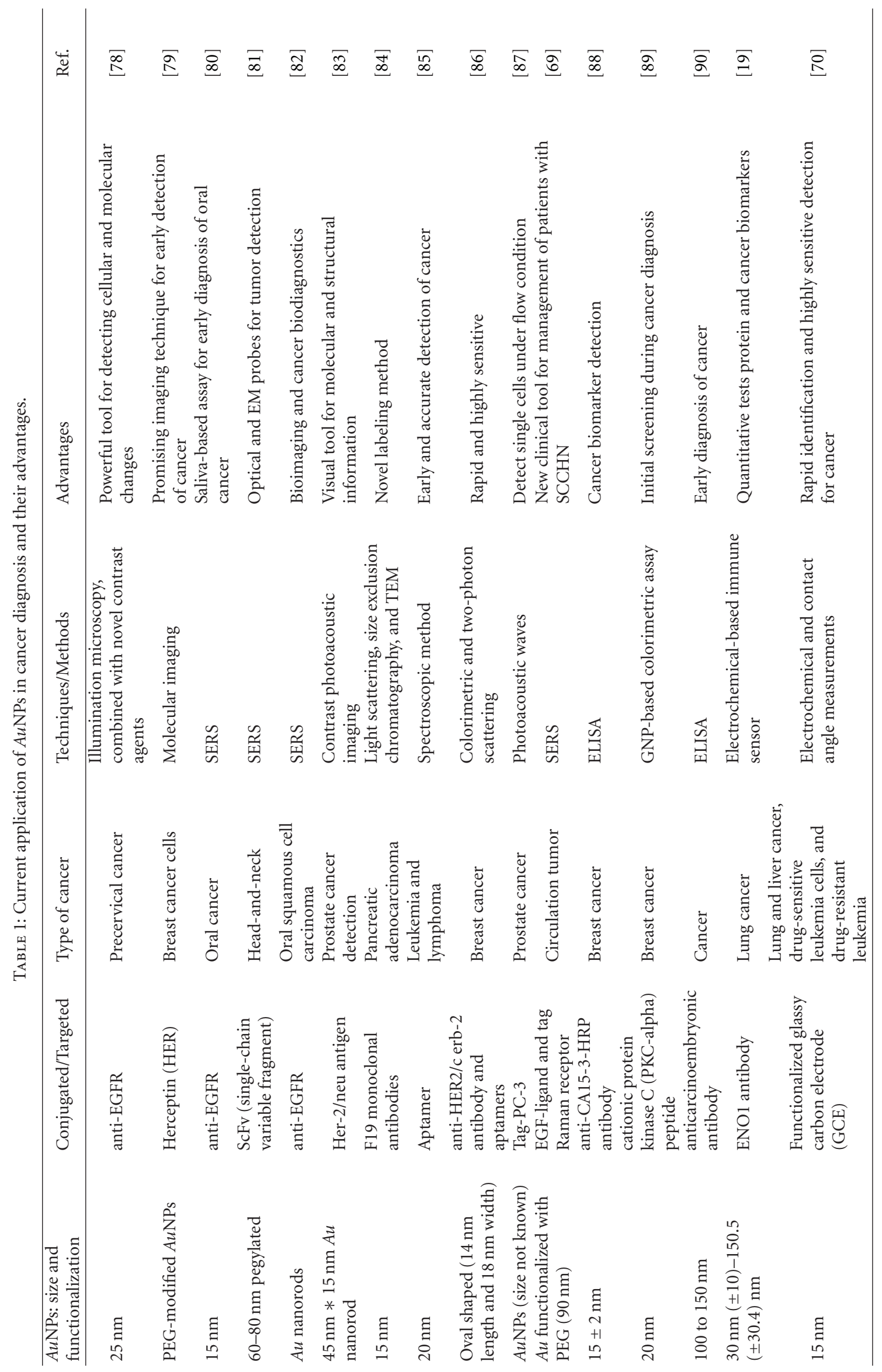




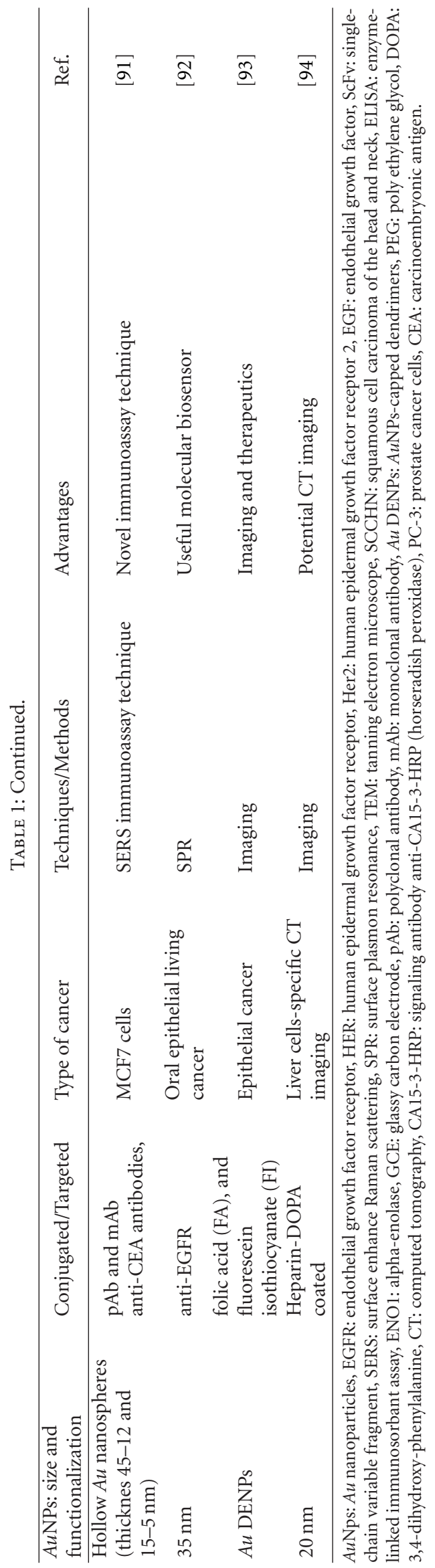



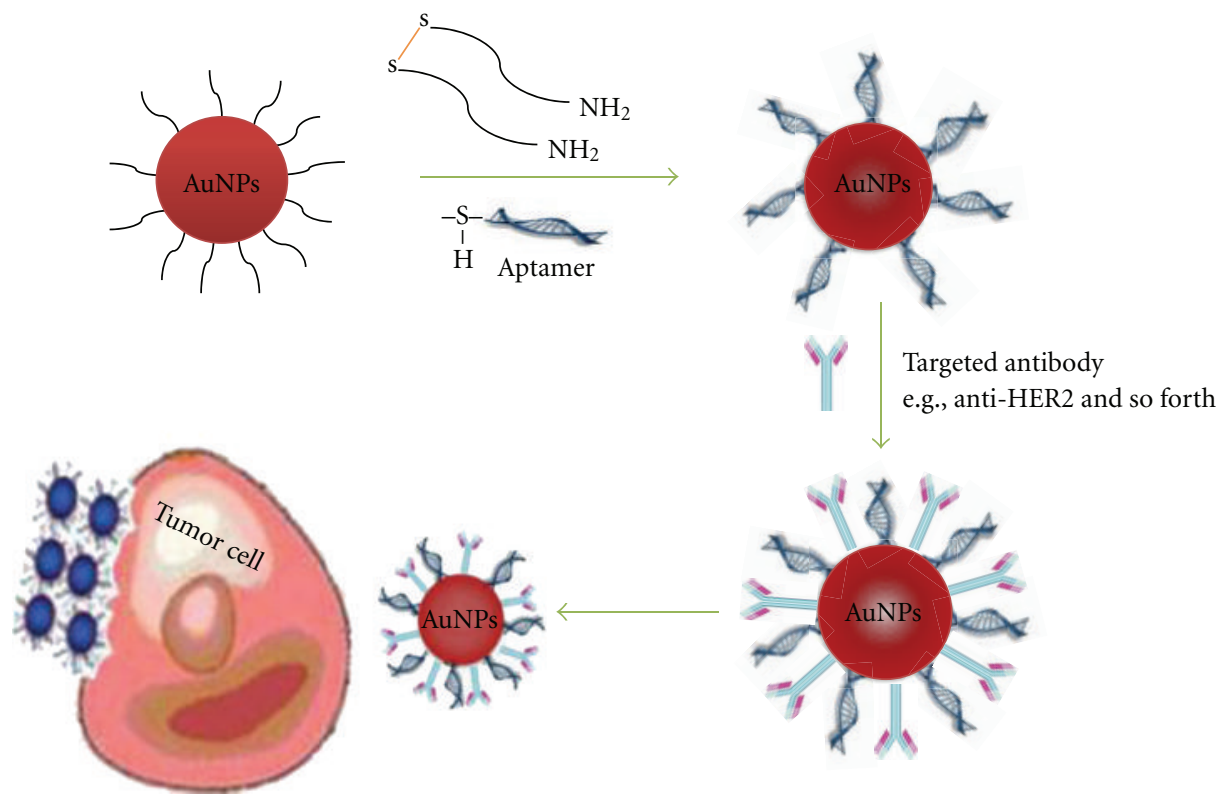

FIGURE 4: Schematic representation of the synthesis of monoclonal anti-HER2 antibody and S6 RNA aptamer-conjugated oval-shaped $A u$ NPs (steps one and two). Third step shows schematic representation of multifunctional oval-shaped $A u$ NP-based sensing of the breast cancer cell lines.

cancer cells expressing their highly specific tumor-associated antigens and poly(ethylene glycol) (PEG) which obscure particles against the reticuloendothelial system in the body [79]. The stability and functionality of Herceptin-polyethylene glycol $A u$ nanorods (Her-PEG $A u$ NRs) were demonstrated in vitro in the presence of blood as well as in vivo in nude mice model for breast cancer. The study showed successful accumulation of functionalized $A u$ NRs within HER2/neu overexpressing breast tumors in tumor-bearing nude mice, thus, providing a novel imaging technique for early detection of cancer. Kah et al. [80] reported colloidal $A u$ NPs conjugated to antiepidermal growth factor receptor (EGFR) for imaging. They have developed a self-assembled surfaceenhanced-Raman-scattering- (SERS-) active AuNPs monolayer film as a biosensing surface using a simple drop-dry method. AuNPs could elicit an optical contrast to discriminate between cancerous and normal cells and their conjugation with antibodies allowed them to map the expression of relevant biomarkers for molecular imaging under confocal reflectance microscopy. Large optical enhancements can be achieved under in vivo conditions for tumor detection using biocompatible and nontoxic NPs based on pegylated $A u$ and surface-enhanced Raman scattering (SERS) properties of NPs. These PEGylated SERS NPs were considerably brighter than semiconductor quantum dots with light emission in the near-infrared region. When conjugated to tumor-targeting ligands such as single-chain variable fragment $(\mathrm{ScFv})$ antibodies, the conjugated NPs were able to target tumor biomarkers such as epidermal growth factor receptors on human cancer cells and in xenograft tumor models [81].

4.2. Diagnosis of Cancer by Colorimetric Assay. Direct-visualization/detection of cancer cells using colorimetric assay has been currently progressing fast due to their simplicity and versatility [112]. AuNPs-conjugated aptamer has been shown to easily assemble on cell membrane surface for spectral changes, providing direct visualization of cancer cells. CellSELEX aptamers have been generated for leukemia, lymphoma, lung cancer, and liver cancer, suggesting that the assays could work out for the detection of these diseases [85]. Recently, $\mathrm{Lu}$ et al. [86] have demonstrated a label-free, fast, and highly sensitive multifunctional oval-shaped $A u$ NPs based on simple colorimetric and highly sensitive two-photon scattering assay for the selective detection of breast cancer (Figure 4). When oval-shaped $A u \mathrm{NPs}$ were mixed with breast cancer SK-BR-3 cell line, a distinct color change occurred, and two-photon scattering intensity was increased by about thirteen times. The method was clearly able to detect the cancerous from noncancerous cells and also distinguished it from other breast cancer cell lines that express low levels of HER2.

Melanin, a natural light absorber in melanoma cells, has been reported to induce photoacoustic waves for tumor cell detection for nonpigmented prostate cancer cell line (PC$3)$. The nonpigmented tumor cells such as breast, prostate, and lung cancers lack intrinsic pigmentation and thus do not generate photoacoustic waves for detection [87]. Utilizing this method on prostate cancer cell line (PC-3), the photoacoustic response over the wavelengths $(470-570 \mathrm{~nm})$ can be determined by tagging them with $A u$ NPs. A new approach for SERS using $A u$ NPs tags can be used for direct measurement of targeted CTCs (circulating tumor cells) in the presence of white blood cells (Figure 5). AuNPs-tagged Raman receptors conjugated with epidermal growth factor (EGF) peptides successfully identified CTCs in the peripheral blood of 19 patients with squamous cell carcinoma of 


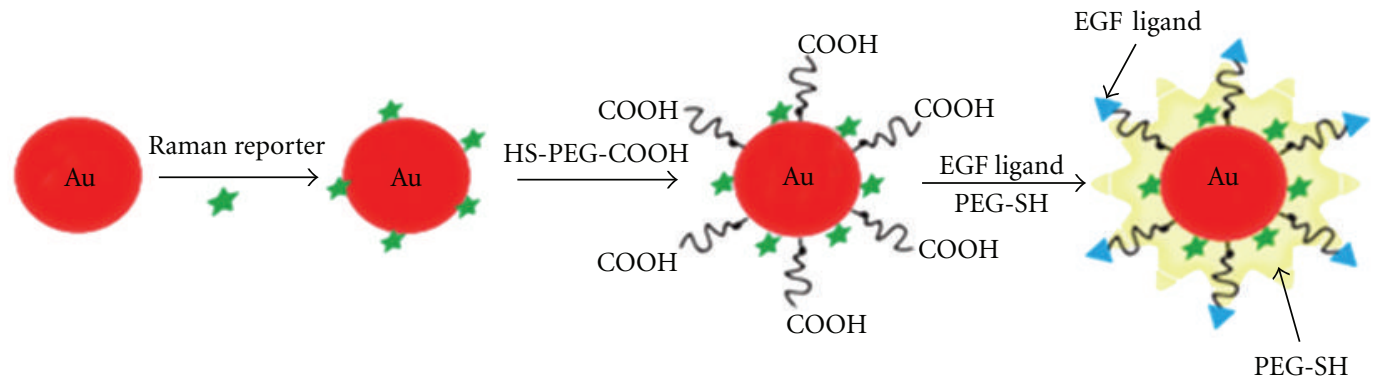

(a)
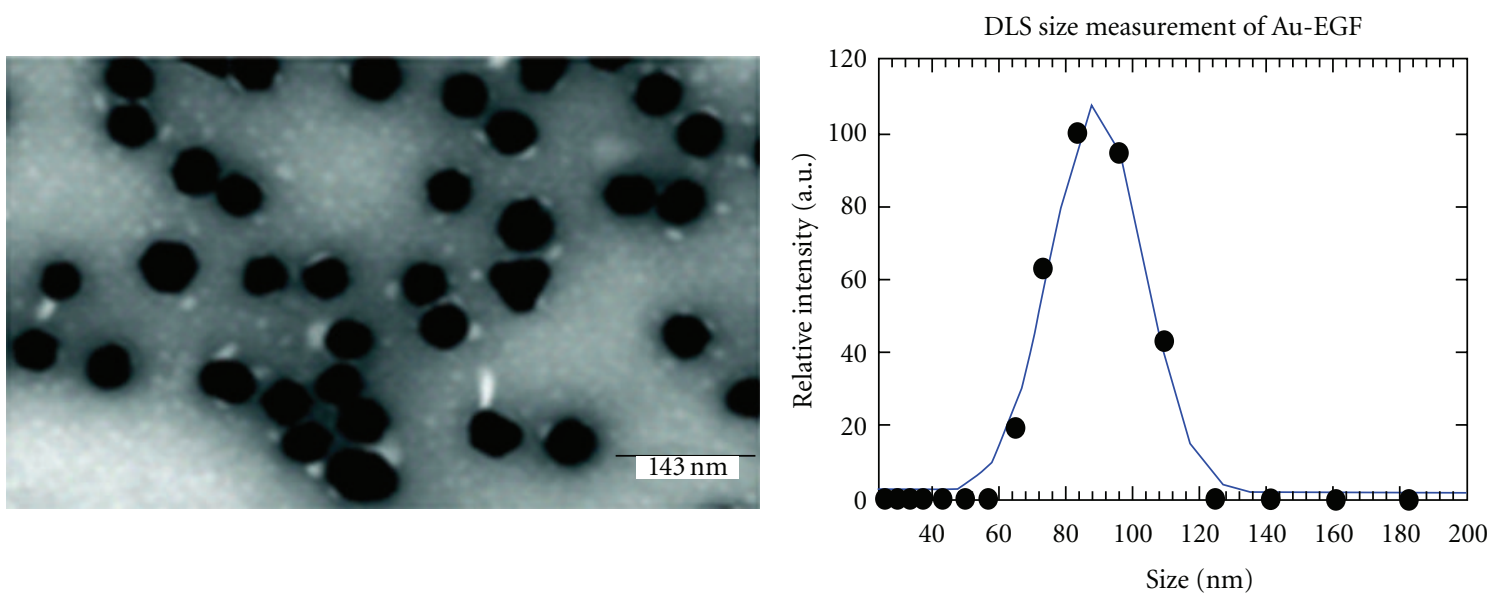

$\stackrel{-}{\longrightarrow} 20 \mathrm{~nm}$

(b)
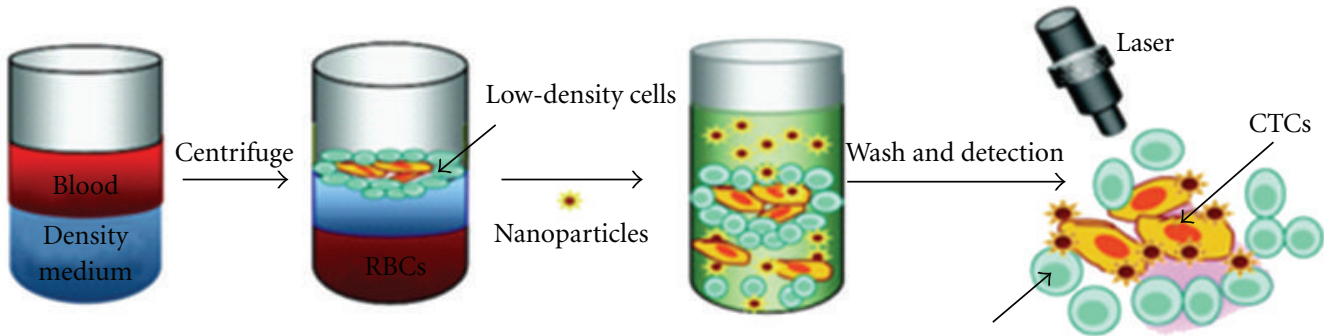

Normal WBCs

(c)

FIGURE 5: Schematic design of EGF-SERS NPs for labeling and detection of CTCs. (a) Raman-encoded, PEG-stabilized, and EGF-peptidefunctionalized SERS nanoparticle. (b) TEM image and DLS measurement of modal system after preparation. (c) Assay principle of CTC detection from whole blood using EGF-SERS nanoparticles. (Reprinted with permission from author, [69]).

the head and neck (SCCHN), within a range of 1-720 CTCs per milliliter of whole blood [69].

\subsection{Detection of Cancer Using Immunoassay and Electrochem-} ical-Based Method. AuNPs can be used as carriers in opticalbased enzyme-linked immunosorbent assay (ELISA) for the analysis of important biomarkers present in blood samples for the treatment of breast cancer. The assay adopting $A u$ NPs as an enhancer resulted in higher sensitivity and shorter assay time when compared to classical method [88]. Kang et al. [89] have developed a noncrosslinking aggregation mechanism with a cationic protein-kinase-C- (PKC- $\alpha$-) specific peptide substrate, which is used as a coagulant of $A u$ NPs with anionic surface. As phosphorylation occurs, the PKC suppressed $A u$ NPs aggregation resulting in red color formation. But in case of nonphosphorylation, the color of the GNP solution changed from red to blue, indicating particle aggregation. Zhou et al. [90] developed a stable AuNPslayer- (GNPL-) modified high-binding ELISA plate method for the representative biomarker carcinoembryonic antigen (CEA) detection. They demonstrated that GNPL markedly amplified the ELISA signal and significantly improved the limit of detection (LOD) and holds great promise in clinical applications for the early diagnosis of cancer. He et al. [70] 

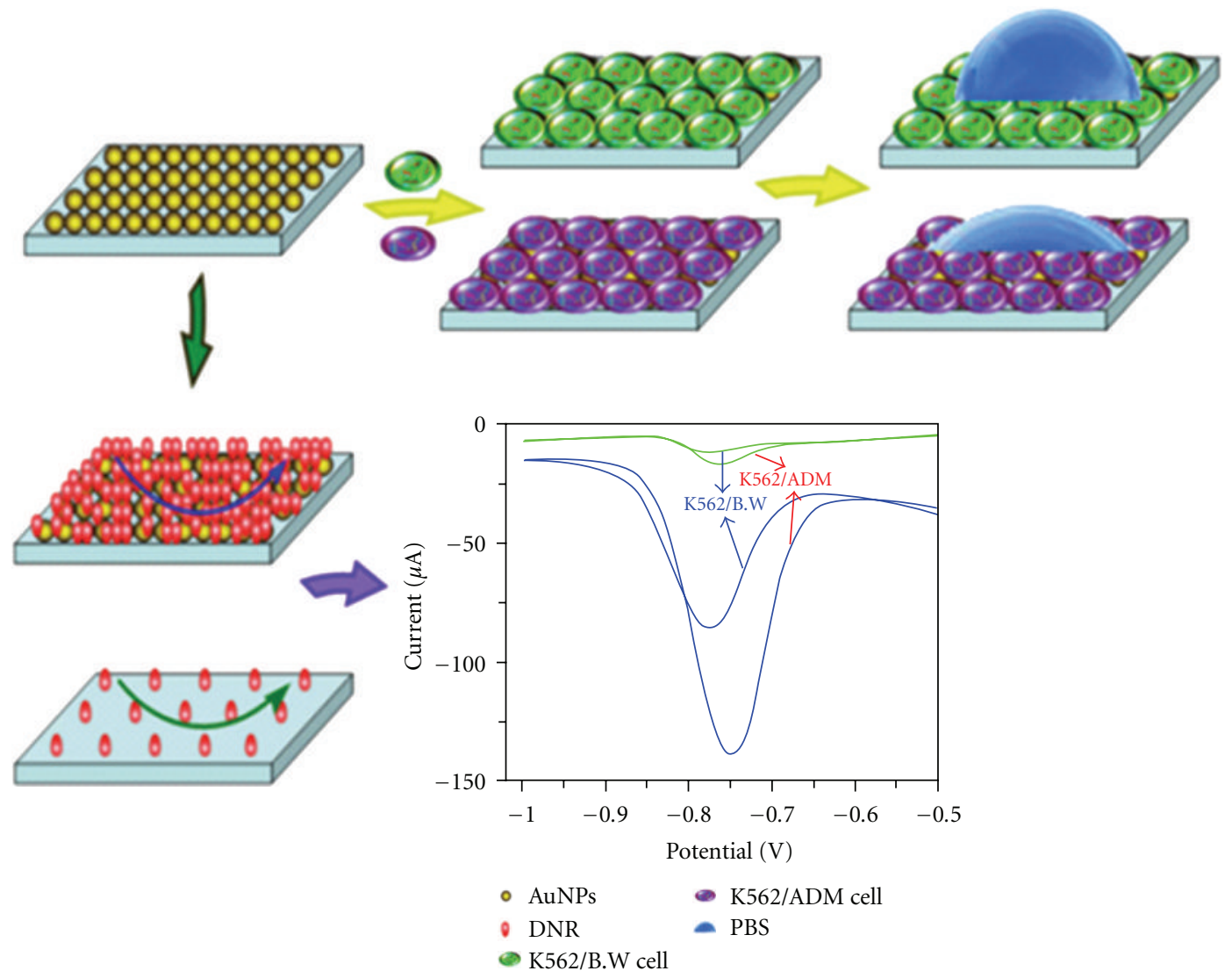

FIGURE 6: Schematic representation of electrochemical and contact angle detection of cancer cells based on functionalized GNPs-GCE interface. (Reprinted with permission from Elsevier, [70]).

demonstrated $A u$ NPs-modified interface for distinguishing different cancer cells, including lung cancer, liver cancer, drug-sensitive leukemia K562/B.W cells, and drug-resistant leukemia K562/ADM cells by using electrochemical and contact angle measurements (Figure 6). In another report, Chon et al. [91] developed a quick and reproducible surfaceenhanced-Raman-scattering- (SERS-) based immunoassay technique, using hollow $A u$ nanospheres (HGNs) and magnetic beads for immunoanalysis of cancer markers.

4.4. Diagnosis of Cancer by Imaging and Microscopy Techniques. In the field of optical imaging techniques, photoacoustic tomography, multiphoton plasmon resonance microscopy, optical coherence microscopy, and third-harmonic microscopy are promising new techniques for the diagnosis of cancer [113]. A general approach for the targeting and imaging of cancer cells using dendrimer-entrapped $A u$ NPs (Au DENPs) was found to be able to covalently link with targeting molecules and imaging ligands. In vitro studies have shown that FA- (folic-acid-) and FI- (fluorescein-isothiocyanate-) modified $A u$ DENPs can specifically bind to KB cells (a human epithelial carcinoma cell line) that overexpress highaffinity folate receptors, and they are internalized dominantly into lysosomes of target cells within $2 \mathrm{~h}$. These findings suggest that $A u$ DENPs may serve as general platform for cancer imaging and therapeutics [93]. Lin et al. [114] developed optical-based diagnostic approach using $A u$ core-shells NPs of different sizes by applying Monte Carlo models which gave extremely tunable optical resonance peak ranging from the near UV to the mid-IR wavelengths. This can well predict the effect of varying concentrations of nanoshells on tissue reflectance. Another simple and inexpensive technique is the dark-field microscopy which can be used for successful detection of cancerous cells. AuNPs conjugated with antiEGFR antibodies immunotargeted two malignant epithelial cell lines, selected for optimal intense SPR using a whitelight source from a conventional microscope, and resulted in a colored $A u \mathrm{NP}$ image with dark background [92].

4.5. Some New Approaches for Diagnosis of Cancer. A new dimension has been added in the diagnosis of cancer by Peng and his coworkers wherein they combined solid-phase microextraction with gas chromatography/mass spectrometry method for identifying volatile organic compounds acting as biomarkers for lung cancer [71]. The $A u$ nanosensor can rapidly distinguish the breath of lung cancer patients from the breath of healthy individuals in an atmosphere of high humidity (Figure 7).

Breast cancer stem cells surface marker can be identified by applying a new approach for dual-mode sensing based on targeting, using pointer and signal enhancement using surface plasmon resonance (SPR) and surface-enhanced Raman 
(i)

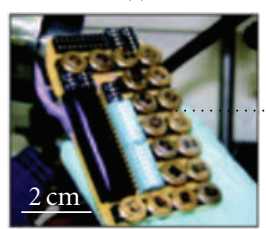

(ii)

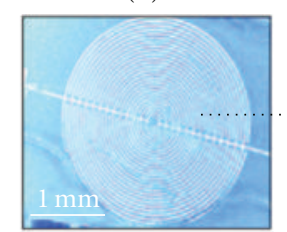

(iii)

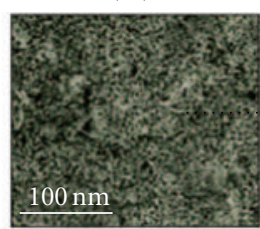

(iv)

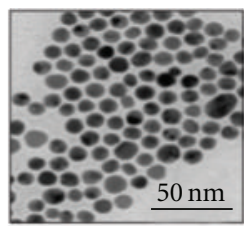

(a)

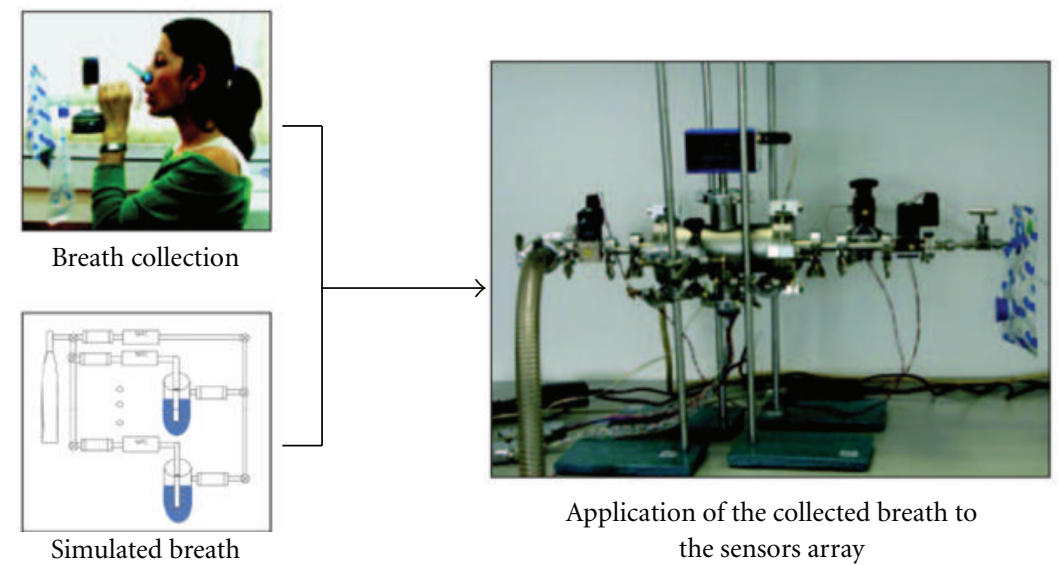

(b)

Figure 7: Breath testing as a method for detecting lung cancer. (a) (i) Array of chemiresistors, (ii) image of chemiresistor using scanning electron microscope (SEM), (iii) image of $A u$ NPs film located between two adjacent electrodes using SEM, and (iv) transmission electron microscope (TEM) image of monolayer-capped $A u$ NPs appearing as dark dots and the capping organic molecules as bright medium between the adjacent dots. The $A u$ NPs in the films provide the necessary electrical conductivity, and the organic film component provides sites for the sorption of analyte molecules. (b) The exhaled breath (from patients) and simulated breath (mixture of representative VOCs at concentrations similar to those determined by GC-MS analysis of exhaled patient's breath) using the array of AuNPs sensors. (Reprinted with permission from Nature Publishing Group, [71]).

scattering (SERS) [115]. By applying these concepts, it was possible to detect the cell surface markers antigen, CD44 and CD24, in three breast cancer cell lines to identify subpopulation $\mathrm{CD} 44^{+} / \mathrm{CD} 24^{-}$of cancer stem cells (CSCs).

\section{Applications of Gold Nanoparticles for Diagnosis of HIV/AIDS}

Inspite of tremendous research undertaken till date to find a cure, HIV/AIDS continues to wreck havoc upon mankind with no cure or preventive vaccine against it. According to the World Health Organisation (WHO), HIV infection in humans is considered to be at pandemic levels. Worldwide, over 33 million people are believed to be living with HIV, while 2 million population met AIDS-related death in 2008. However, many of these deaths may have been preventable if access to appropriate diagnostics and therapies method would have been possible.

Advances in nanotechnology have led to the development of $A u$ NP-based biobarcode amplification assay (BCA), which can detect HIV-1 p24 antigen at very low concentration levels $(0.1 \mathrm{pg} / \mathrm{mL})$. The limit of detection was $10-15 \mathrm{pg} / \mathrm{mL}$, and these results demonstrated that HIV-1 p24 BCA assay offers 100-150-fold enhancement in the detection limit over the traditional ELISA method. In the second set, they used the Europium-based NPs for immunoassay instead of $A u$ NPs in the BCA assay to further simplify the detection method and decrease the incubation time. In this case, the lower limit of detection for HIV-1 p24 was $0.5 \mathrm{pg} / \mathrm{mL}$. This universal labeling technology based on NPs and its application may provide a rapid and sensitive testing platform for clinical diagnosis for HIV [116].

Another technique that holds promise is the visual DNA microarray for simultaneous, sensitive, and specific detection of human immunodeficiency virus type-1 (HIV-1) based on $A u$-labelled silver staining and coupled with multiplex asymmetric polymerase chain reaction (PCR). The $5^{\prime}$-end amino-modified oligonucleotides were immobilized on glass surface, which were used as the capturing probes to bind the complementary biotinylated target DNA. When $A u$ conjugated streptavidins were introduced to the microarray for specific binding to biotin molecules, it gave rise to black image of microarray spots, which is the result of the formation of silver precipitate onto $A u N P s$ and bound to streptavidins. A total of 169 clinical samples of HIV-1 and T. pallidum from infected patients were tested through this method. Overall, the results demonstrate that visual gene 


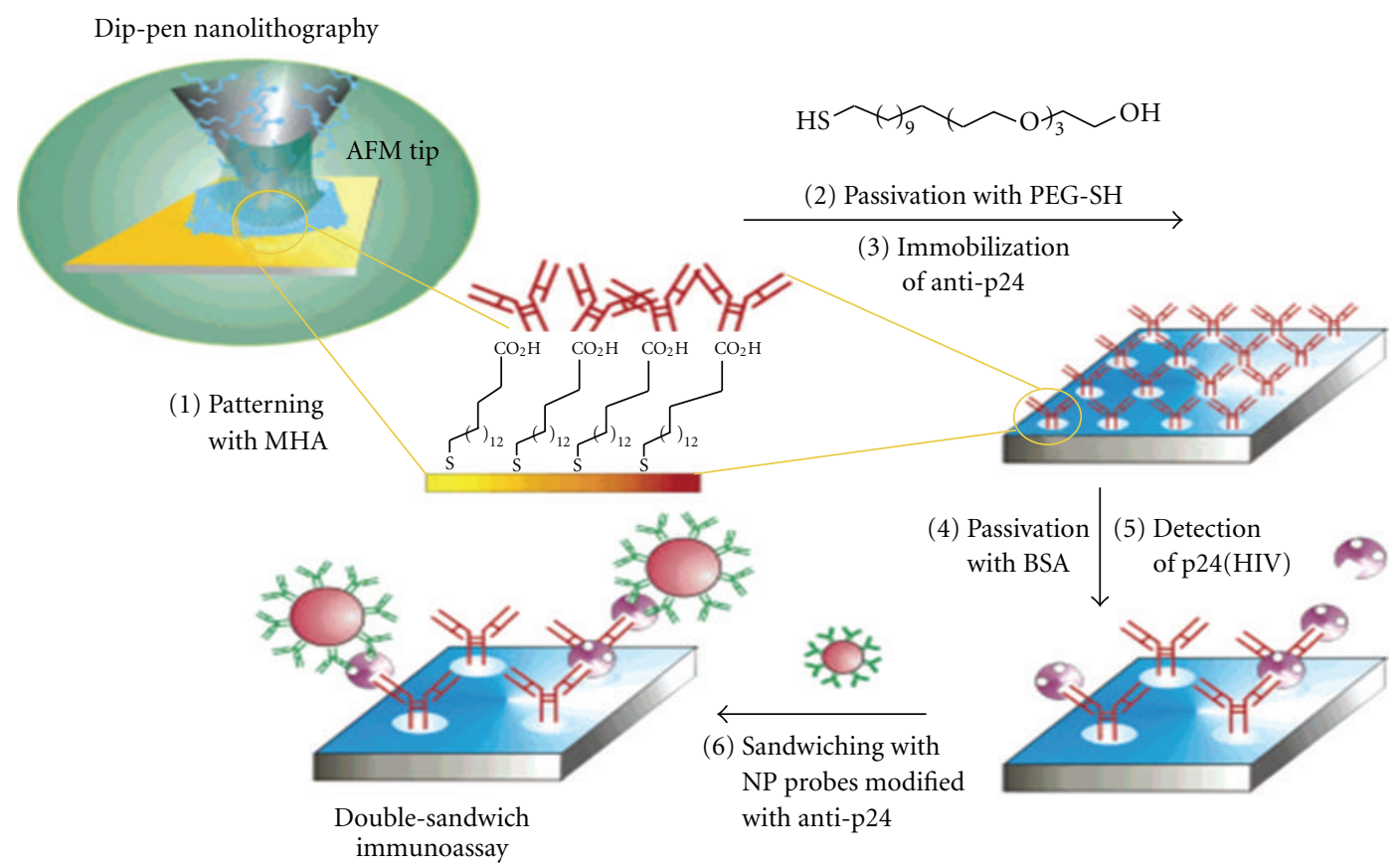

FIGURE 8: Illustration of the immunoassay model used in the detection of HIV-1 p24 antigen with anti-p24 antibody nanoarray. (1) patterning process, (2) and (3) passivated process of $A u$ with PEG-SH, (4) and (5) Passivated with BSA and detection of p24(HIV), and (6) sandwich process with nanoprobe modified with p24 (HIV) (Reprinted with permission from American Chemical Society, [72]).

detection technique offers high sensitivity and specificity for the clinical applications in case of diseases like HIV [117].

Bowman et al. [118] documented the first ever application of small molecule, SDC-1721 (a derivative of the potent HIV inhibitor, TAK-779) coated with 2-nm AuNPmercaptobenzoic acid, as effective inhibitors of HIV fusion. TAK-779 is a known CCR5 antagonist that serves as the main entry coreceptor for most commonly transmitted and infectious strains of HIV-1. In this way, TAK-779 inhibited HIV-1 replication with an IC 50 of $10 \mathrm{nM}$. Similarly, $2 \mathrm{~nm}$ $A u$ NPs coated with multiple copies of an amphiphilic sulfateended ligand were developed which were able to bind the HIV envelope glycoprotein gp120 [119]. SPR results of in vitro $\mathrm{HIV}$ infection of $\mathrm{T}$ cells at nanomolar concentrations revealed high levels of inhibition. These results suggest the possibility of tailoring both sulfated ligands and other antiHIV molecules on the same $A u$ cluster, thus contributing to the development of anti-HIV therapeutics as well as for diagnosis purpose. Lee et al. [72] reported the application of nanometer-scale antibody array-based analysis to determine the human immunodeficiency virus type-1 (HIV-1) in blood samples. In this method, Dip-pen nanolithography (DPN) was used to generate nanoscale patterns of antibodies against the HIV-1 p24 antigen on $A u$ surface. The HIV-1 p24 antigen in plasma sample was hybridized to the antibody array in situ, and the bound protein was hybridized to an $A u$ antibodyfunctionalized nanoparticle probe for signal enhancement. The nanoarray features in the three-component sandwich assay were confirmed by atomic force microscopy (AFM). The amount of HIV-1 p24 antigen measure in plasma was less than 50 copies of RNA per mililiter of plasma (corresponding to $0.025 \mathrm{pg} / \mathrm{mL}$ ) (Figure 8).
Mahmoud et al. [120, 121] have suggested the possibility of electrochemical detection of HIV type-1 protease (HIV1 PR) using ferrocene- (Fc-) pepstatin-modified surfaces in picomolar level. In this experiment, they modified the $A u$ electrode surface using $A u$ NPs or thiolated single-walled carbon nanotubes/gold nanoparticles (SWCNT/AuNP). The thiol-terminated Fc-pepstatin was then self-assembled on such surfaces as confirmed by raman spectroscopy and scanning electron microscope (SEM) techniques. The exact interaction between the Fc-pepstatin-modified substrates and HIV-1 PR was studied by cyclic voltametry and electrochemical spectroscopy. The sensing electrode modified with thiolated SWCNTs/AuNPs showed remarkable detection and high sensitivity with an estimated detection limit of 0.8 picomolar (pM).

Darbha et al. [122] demonstrated a label-free, highly sensitive, rapid, easy, and reliable diagnosis of single-basemismatch HIV-1 virus DNA by measuring the HRS (hyperRayleigh scatter) intensity from DNA-modified $A u$ NRs. They provide higher multipolar contribution to nonlinear optical response (NLO) of $A u$ NRs to approach this result. The advantages of this assay are (i) to use unmodified protein and DNA to probe them in solution by the HRS technique, (ii) it can be two orders of magnitude more sensitive than the usual colorimetric technique, and (iii) single-base-pair mismatches are easily detected.

\section{Conclusion}

It is clear that $A u$ NPs offer various advantages over bulk structures; their characteristic properties make them ideal for diagnostic purpose and several biomedical applications. 
A number of techniques applying with $A u$ NPs such as surface chemistry mainly by conjugating them with biological molecules have been playing a great role in 21th century for the diagnosis and treatment of various diseases like cancer and HIV. Surface plasmon resonance (SPR) is significant for the absorption and scattering properties of $A u$ NPs [123]. The last 20 years have seen tremendous development of SPR and its use in biomedical applications related to diagnostics and therapy. This technique applies not only for measuring real-time kinetics of ligand-receptor interactions, but also for the screening of lead compound identification in the pharmaceutical drug development, and for the detection of small molecules [54-68, 73-77, 95]. Modern and highly advanced spectroscopic techniques based upon SERS [124] provide a huge enhancement of the Raman signal, by a factor of ca. $10^{14}-10^{15}$, allowing detection at the single-molecule level in pico/nanoconcentration [35]. The most promising applications of $A u$ NPs in cancer are tumor detection, molecular imaging, multiplex diagnostic, and fluoroimmunoassay. All these together have boosted the immense potential of $A u$ NPs and would shed light on various applications of biomedical field.

Currently, there is no cure, preventive vaccine, and appropriate diagnosis for HIV/AIDS. According to the World Health Organisation, HIV infection in humans is considered to be at pandemic level. Colloidal $A u$ is suitable for longterm storage and, therefore, can be used in the typical African climate and in remote area. AuNP-based biobarcode amplification (BCA) assay can detect HIV-1 p24 antigen at levels as low as $0.1 \mathrm{pg} / \mathrm{mL}$ [116]. In the recent years, protein microarray detection strategies and Protein Chip System for parallel analysis of multitumor markers and its application in cancer detection have also been developed [125].

However despite rapid advancement in research, new cancer cases have been still increasing. Therefore, to attract the use of NPs more towards the biological field, new synthesis, fabrication, and characterization methods are needed for developing highly advanced NPs capable of use in sensitive and multiple detection methods with negligible toxicity.

To conclude, engineering the NPs in different directions and ability to tailor the physicochemical properties have together given a right way to make the material more advanced and highly robust for the binding affinities of various biomolecules and drug targets for the diagnosis and treatment of disease like cancer and HIV. In future, it might be possible to apply all these properties together and evolve new chemistry for synthesis of smart materials for diagnostic applications.

\section{Acknowledgments}

This work was supported in part by Chinese Natural Science Foundation project (no. 30970784), National Key Basic Research Program of China (2009CB930200), Chinese Academy of Sciences (CAS) "Hundred Talents Program" (07165111ZX), and CAS Knowledge Innovation Program.

\section{References}

[1] N. L. Rosi and C. A. Mirkin, "Nanostructures in biodiagnostics," Chemical Reviews, vol. 105, no. 4, pp. 1547-1562, 2005.
[2] P. Baudhuin, P. vander Smissen, S. Beavois, and J. Courtoy, "Molecular interactions between colloidal gold, proteins, and living cells," in Colloidal Gold: Principles, Methods, and Applications, M. A. Hayat, Ed., vol. 1-2, Academic Press, 1989.

[3] X. J. Liang, C. Chen, Y. Zhao, L. Jia, and P. C. Wang, "Biopharmaceutics and therapeutic potential of engineered nanomaterials," Current Drug Metabolism, vol. 9, no. 8, pp. 697709, 2008.

[4] P. Alivisatos, "The use of nanocrystals in biological detection,” Nature Biotechnology, vol. 22, no. 1, pp. 47-52, 2004.

[5] R. C. Jin, Y. C. Cao, E. Hao, G. S. Metraux, G. C. Schatz, and C. A. Mirkin, "Controlling anisotropic nanoparticle growth through plasmon excitation," Nature, vol. 425, no. 6957, pp. 487-490, 2003.

[6] Y. G. Sun and Y. N. Xia, "Shape-controlled synthesis of gold and silver nanoparticles," Science, vol. 298, no. 5601, pp. 2176-2179, 2002.

[7] T. K. Sau and C. J. Murphy, "Room temperature, high-yield synthesis of multiple shapes of gold nanoparticles in aqueous solution," Journal of the American Chemical Society, vol. 126, no. 28, pp. 8648-8649, 2004.

[8] Y. Cui, Q. Wei, H. Park, and C. M. Lieber, "Nanowire nanosensors for highly sensitive and selective detection of biological and chemical species," Science, vol. 293, no. 5533, pp. 1289-1292, 2001.

[9] D. S. Ginger, H. Zhang, and C. A. Mirkin, "The evolution of dip-pen nanolithography," Angewandte Chemie, vol. 43, no. 1 , pp. 30-45, 2004.

[10] K. Wadu-Mesthrige, S. Xu, N. A. Amro, and G. Y. Liu, "Fabrication and imaging of nanometer-sized protein patterns," Langmuir, vol. 15, no. 25, pp. 8580-8583, 1999.

[11] M. Z. Liu, N. A. Amro, C. S. Chow, and G. Y. Liu, "Production of nanostructures of DNA on surfaces," Nano Letters, vol. 2, no. 8, pp. 863-867, 2002.

[12] J. R. Kenseth, J. A. Harnisch, V. W. Jones, and M. D. Porter, "Investigation of approaches for the fabrication of protein patterns by scanning probe lithography," Langmuir, vol. 17, no. 13 , pp. 4105-4112, 2001.

[13] C. A. Mirkin, R. L. Letsinger, R. C. Mucic, and J. J. Storhoff, "A DNA-based method for rationally assembling nanoparticles into macroscopic materials," Nature, vol. 382, no. 6592, pp. 607-609, 1996.

[14] M. Endo, Y. Katsuda, K. Hidaka, and H. Sugiyama, "Regulation of DNA methylation using different tensions of double strands constructed in a defined DNA nanostructure," Journal of the American Chemical Society, vol. 132, no. 5, pp. 1592-1597, 2010.

[15] L. J. Wang Yz Hb and X. J. Liang, "Current status of nanotechnology applied in biomedicine," Acta Biophysica Sinica, vol. 25, no. 3, pp. 168-174, 2009.

[16] R. J. Chen, Y. Zhang, D. Wang, and H. Dai, "Noncovalent sidewall functionalization of single-walled carbon nanotubes for protein immobilization," Journal of the American Chemical Society, vol. 123, no. 16, pp. 3838-3839, 2001.

[17] M. C. Daniel and D. Astruc, "Gold Nanoparticles: assembly, supramolecular chemistry, quantum-size-related properties, and applications toward biology, catalysis, and nanotechnology," Chemical Reviews, vol. 104, no. 1, pp. 293-346, 2004.

[18] K. S. Soppimath, G. V. Betageri, and M. H. Cho, "Nanosctructures for cancer diagnostics and therapy," in Biomedical Nanostructures, K. Gonsalves, C. Halberstadt, C. Laurencin, and L. Nair, Eds., pp. 409-437, John Wiley \& Sons, New York, NY, USA, 2008. 
[19] J. A. A. Ho, H. C. Chang, N. Y. Shih et al., "Diagnostic detection of human lung cancer-associated antigen using a gold nanoparticle-based electrochemical immunosensor," Analytical Chemistry, vol. 82, no. 14, pp. 5944-5950, 2010.

[20] H. Devalapally, D. Shenoy, S. Little, R. Langer, and M. Amiji, "Poly(ethylene oxide)-modified poly( $\beta$-amino ester) nanoparticles as a $\mathrm{pH}$-sensitive system for tumor-targeted delivery of hydrophobic drugs: part 3. Therapeutic efficacy and safety studies in ovarian cancer xenograft model," Cancer Chemotherapy and Pharmacology, vol. 59, no. 4, pp. 477-484, 2007.

[21] D. Shenoy, S. Little, R. Langer, and M. Amiji, "Poly(ethylene oxide)-modified poly ( $\beta$-amino ester $)$ nanoparticles as a $\mathrm{pH}$ sensitive system for tumor-targeted delivery of hydrophobic drugs: part 2. In vivo distribution and tumor localization studies," Pharmaceutical Research, vol. 22, no. 12, pp. 21072114, 2005.

[22] O. C. Farokhzad, J. Cheng, B. A. Teply et al., "Targeted nanoparticle-aptamer bioconjugates for cancer chemotherapy in vivo," Proceedings of the National Academy of Sciences of the United States of America, vol. 103, no. 16, pp. 6315-6320, 2006.

[23] Gold for good, "Gold and nanotechnology in the age of innovation," http://www.gold.org/download/rs_archive/gold_ and_nanotechnology_in_the_age_of_innovation.pdf\#.

[24] C. Burda, X. Chen, R. Narayanan, and M. A. El-Sayed, "Chemistry and properties of nanocrystals of different shapes," Chemical Reviews, vol. 105, no. 4, pp. 1025-1102, 2005.

[25] E. Katz and I. Willner, "Integrated nanoparticle-biomolecule hybrid systems: synthesis, properties, and applications," Angewandte Chemie, vol. 43, no. 45, pp. 6042-6108, 2004.

[26] G. M. Whitesides, "The "right" size in nanobiotechnology," Nature Biotechnology, vol. 21, no. 10, pp. 1161-1165, 2003.

[27] J. Wilcoxon, "Optical absorption properties of dispersed gold and silver alloy nanoparticles," Journal of Physical Chemistry $B$, vol. 113, no. 9, pp. 2647-2656, 2009.

[28] P. N. Njoki, I. I. S. Lim, D. Mott et al., "Size correlation of optical and spectroscopic properties for gold nanoparticles," Journal of Physical Chemistry C, vol. 111, no. 40, pp. 14664 14669, 2007.

[29] I. O. Sosa, C. Noguez, and R. G. Barrera, "Optical properties of metal nanoparticles with arbitrary shapes," Journal of Physical Chemistry B, vol. 107, no. 26, pp. 6269-6275, 2003.

[30] S. Link, M. B. Mohamed, and M. A. El-Sayed, "Simulation of the optical absorption spectra of gold nanorods as a function of their aspect ratio and the effect of the medium dielectric constant," Journal of Physical Chemistry B, vol. 103, no. 16, pp. 3073-3077, 1999.

[31] S. Link and M. A. El-Sayed, "Simulation of the optical absorption spectra of gold nanorods as a function of their aspect ratio and the effect of the medium dielectric constant," Journal of Physical Chemistry B, vol. 109, no. 20, pp. 1053110532, 2005.

[32] M. Losurdo, M. M. Giangregorio, G. V. Bianco et al., "Size dependence of the dielectric function of silicon-supported plasmonic gold nanoparticles," Physical Review B, vol. 82, no. 15, Article ID 155451, 25 pages, 2010.

[33] P. K. Jain, K. S. Lee, I. H. El-Sayed, and M. A. El-Sayed, "Calculated absorption and scattering properties of gold nanoparticles of different size, shape, and composition: applications in biological imaging and biomedicine," Journal of Physical Chemistry B, vol. 110, no. 14, pp. 7238-7248, 2006.
[34] K. S. Lee and M. A. El-Sayed, "Dependence of the enhanced optical scattering efficiency relative to that of absorption for gold metal nanorods on aspect ratio, size, end-cap shape, and medium refractive index," Journal of Physical Chemistry B, vol. 109, no. 43, pp. 20331-20338, 2005.

[35] C. Sonnichsen, B. M. Reinhard, J. Liphardt, and A. P. Alivisatos, "A molecular ruler based on plasmon coupling of single gold and silver nanoparticles," Nature Biotechnology, vol. 23, no. 6, pp. 741-745, 2005.

[36] J. Perez-Juste, I. Pastoriza-Santos, L. M. Liz-Marzan, and P. Mulvaney, "Gold nanorods: synthesis, characterization and applications," Coordination Chemistry Reviews, vol. 249, no. 17-18, pp. 1870-1901, 2005.

[37] K. Kneipp, H. Kneipp, and J. Kneipp, "Surface-enhanced raman scattering in local optical fields of silver and gold nanoaggregates-from single-molecule raman spectroscopy to ultrasensitive probing in live cells," Accounts of Chemical Research, vol. 39, no. 7, pp. 443-450, 2006.

[38] C. Zhang, Z. Zhang, B. Yu, J. Shi, and X. Zhang, "Application of the biological conjugate between antibody and colloid $\mathrm{Au}$ nanoparticles as analyte to inductively coupled plasma mass spectrometry," Analytical Chemistry, vol. 74, no. 1, pp. 96-99, 2002.

[39] X. Li, L. Jiang, Q. Zhan, J. Qian, and S. He, "Localized surface plasmon resonance (LSPR) of polyelectrolyte-functionalized gold-nanoparticles for bio-sensing," Colloids and Surfaces A, vol. 332, no. 2-3, pp. 172-179, 2009.

[40] W. P. Hall, S. N. Ngatia, and R. P. VanDuyne, "LSPR biosensor signal enhancement using nanoparticle-antibody conjugates," Journal of Physical Chemistry C, vol. 115, no. 5, pp. 1410-1414, 2011.

[41] P. Englebienne, Immune and Receptor Assays in Theory and Practice, CRC Press, Boca Raton, Fla, USA, 2000.

[42] S. Nishimura, T. Yoshidome, W. Kyuutoku, M. Mitsushio, and M. Higo, "Characteristics of a surface plasmon resonance sensor combined with a poly(vinyl chloride) film-based ionophore technique for metal ion analyses," Analytical Sciences, vol. 18, no. 3, pp. 267-271, 2002.

[43] A. Kugimiya and T. Takeuchi, "Surface plasmon resonance sensor using molecularly imprinted polymer for detection of sialic acid," Biosensors \& Bioelectronics, vol. 16, no. 9-12, pp. 1059-1062, 2001.

[44] L. Tong, Q. Wei, A. Wei, and J. X. Cheng, "Gold nanorods as contrast agents for biological imaging: optical properties, surface conjugation and photothermal effects," Photochemistry and Photobiology, vol. 85, no. 1, pp. 21-32, 2009.

[45] P. Englebienne, A. Van Hoonacker, and M. Verhas, "Surface plasmon resonance: principles, methods and applications in biomedical sciences," Spectroscopy, vol. 17, no. 2-3, pp. 255273, 2003.

[46] J. Matsui, K. Akamatsu, N. Hara et al., "SPR sensor chip for detection of small molecules using molecularly imprinted polymer with embedded gold nanoparticles," Analytical Chemistry, vol. 77, no. 13, pp. 4282-4285, 2005.

[47] A. J. Thiel, A. G. Frutos, and C. E. Jordan, "In situ surface plasmon resonance imaging detection of DNA hybridization to oligonucleotide arrays on gold surfaces," Analytical Chemistry, vol. 69, no. 24, pp. 4948-4956, 1997.

[48] L. K. Wolf, Y. Gao, and R. M. Georgiadis, "Kinetic discrimination of sequence-specific DNA-drug binding measured by surface plasmon resonance imaging and comparison to solution-phase measurements," Journal of the American Chemical Society, vol. 129, no. 34, pp. 10503-10511, 2007. 
[49] C. E. Jordan, A. G. Frutos, A. J. Thiel, and R. M. Corn, "Surface plasmon resonance imaging measurements of DNA hybridization adsorption and streptavidin/DNA multilayer formation at chemically modified gold surfaces," Analytical Chemistry, vol. 69, no. 24, pp. 4939-4947, 1997.

[50] B. P. Nelson, T. E. Grimsrud, M. R. Liles, R. M. Goodman, and R. M. Corn, "Surface plasmon resonance imaging measurements of DNA and RNA hybridization adsorption onto DNA microarrays," Analytical Chemistry, vol. 73, no. 1, pp. $1-7,2001$.

[51] Y. Iwasaki, T. Horiuchi, and O. Niwa, "Detection of electrochemical enzymatic reactions by surface plasmon resonance measurement," Analytical Chemistry, vol. 73, no. 7, pp. 15951598, 2001.

[52] K. Matsumoto, A. Torimaru, S. Ishitobi et al., "Preparation and characterization of a polyclonal antibody from rabbit for detection of trinitrotoluene by a surface plasmon resonance biosensor," Talanta, vol. 68, no. 2, pp. 305-311, 2005.

[53] M. B. Medina, "Hygromycin B antibody production and characterization by a surface plasmon resonance biosensor," Journal of Agricultural and Food Chemistry, vol. 45, no. 2, pp. 389-394, 1997.

[54] C. S. Bich, M. Scott, A. Panagiotidis, R. J. Wenzel, A. Nazabal, and R. Zenobi, "Characterization of antibody-antigen interactions: comparison between surface plasmon resonance measurements and high-mass matrix-assisted laser desorption/ionization mass spectrometry," Analytical Biochemistry, vol. 375 , no. 1 , pp. 35-45, 2008.

[55] E. Kaganer, R. Pogreb, D. Davidov, and I. Willner, "Surface plasmon resonance characterization of photoswitchable antigen-antibody interactions," Langmuir, vol. 15, no. 11, pp. 3920-3923, 1999.

[56] G. J. Wegner, H. J. Lee, and R. M. Corn, "Characterization and optimization of peptide arrays for the study of epitopeantibody interactions using surface plasmon resonance imaging," Analytical Chemistry, vol. 74, no. 20, pp. 5161-5168, 2002.

[57] H. X. Chen, J. Huang, J. Lee, S. Hwang, and K. Koh, "Surface plasmon resonance spectroscopic characterization of antibody orientation and activity on the calixarene monolayer," Sensors and Actuators B, vol. 147, no. 2, pp. 548-553, 2010.

[58] B. Johne, "Epitope mapping by surface plasmon resonance in the BIAcore," Molecular Biotechnology, vol. 9, no. 1, pp. 65$71,1998$.

[59] V. Towne, Y. Wang, C. B. Oswald et al., "Epitope characterization of human papillomavirus type 16 virus-like particle through pair-wise antibody footprinting using surface plasmon resonance based biosensor technology," Abstracts of Papers of the American Chemical Society, vol. 228, pp. U201U202, 2004.

[60] S. Chah, M. R. Hammond, and R. N. Zare, "Gold nanoparticles as a colorimetric sensor for protein conformational changes," Chemistry and Biology, vol. 12, no. 3, pp. 323-328, 2005.

[61] H. Z. Huang, P. Ran, and Z. Liu, "Signal enhancement of surface plasmon resonance-based immunoassays for the allergen detection," Sensors and Actuators B, vol. 131, no. 2, pp. 417-423, 2008.

[62] D. R. Shankaran and N. Miura, "Trends in interfacial design for surface plasmon resonance based immunoassays," Journal of Physics D, vol. 40, no. 23, pp. 7187-7200, 2007.

[63] W. M. Mullett, E. P. C. Lai, and J. M. Yeung, "Surface plasmon resonance-based immunoassays," Methods, vol. 22, no. 1, pp. 77-91, 2000.
[64] E. Boisselier and D. Astruc, "Gold nanoparticles in nanomedicine: preparations, imaging, diagnostics, therapies and toxicity," Chemical Society Reviews, vol. 38, no. 6, pp. 17591782, 2009.

[65] D. X. Cui and D. P. Yang, "Advances and prospects of gold nanorods," Chemistry, vol. 3, no. 12, pp. 2010-2022, 2008.

[66] S. Lal, S. E. Clare, and N. J. Halas, "Nanoshell-enabled photothermal cancer therapy: impending clinical impact," Accounts of Chemical Research, vol. 41, no. 12, pp. 1842-1851, 2008.

[67] A. Ben-Yakar, N. J. Durr, T. Larson, D. K. Smith, B. A. Korgel, and K. Sokolov, "Two-photon luminescence imaging of cancer cells using molecularly targeted gold nanorods," Nano Letters, vol. 7, no. 4, pp. 941-945, 2007.

[68] M. Hu, J. Chen, Z. Y. Li et al., "Gold nanostructures: engineering their plasmonic properties for biomedical applications," Chemical Society Reviews, vol. 35, no. 11, pp. 10841094, 2006.

[69] X. Wang, X. Qian, J. J. Beitler et al., “Detection of circulating tumor cells in human peripheral blood using surfaceenhanced raman scattering nanoparticles," Cancer Research, vol. 71, no. 5, pp. 1526-1532, 2011.

[70] F. He, Q. Shen, H. Jiang et al., "Rapid identification and high sensitive detection of cancer cells on the gold nanoparticle interface by combined contact angle and electrochemical measurements," Talanta, vol. 77, no. 3, pp. 1009-1014, 2009.

[71] G. Peng, U. Tisch, O. Adams et al., "Diagnosing lung cancer in exhaled breath using gold nanoparticles," Nature Nanotechnology, vol. 4, no. 10, pp. 669-673, 2009.

[72] K. B. Lee, E. Y. Kim, C. A. Mirkin, and S. M. Wolinsky, “The use of nanoarrays for highly sensitive and selective detection of human immunodeficiency virus type 1 in plasma," Nano Letters, vol. 4, no. 10, pp. 1869-1872, 2004.

[73] E. A. Wallnofer, G. C. Thurner, A. A. Abdelmoez et al., "MRI molecular imaging with nanoparticles: a technical platform for early diagnosis of cancer," International Journal of Clinical Pharmacology and Therapeutics, vol. 49, no. 1, pp. 73-74, 2011.

[74] M. A. Hahn, A. K. Singh, P. Sharma, S. C. Brown, and B. M. Moudgil, "Nanoparticles as contrast agents for in-vivo bioimaging: current status and future perspectives," Analytical and Bioanalytical Chemistry, vol. 399, no. 1, pp. 3-27, 2011.

[75] L. Moriggi, C. Cannizzo, E. Dumas, C. R. Mayer, A. Ulianov, and L. Helm, "Gold nanoparticles functionalized with gadolinium chelates as high-relaxivity MRI contrast agents," Journal of the American Chemical Society, vol. 131, no. 31, pp. 10828-10829, 2009.

[76] C. Alric, R. Serduc, C. Mandon et al., "Gold nanoparticles designed for combining dual modality imaging and radiotherapy," Gold Bulletin, vol. 41, no. 2, pp. 90-97, 2008.

[77] S. J. Cho, B. R. Jarrett, A. Y. Louie, and S. M. Kauzlarich, "Gold-coated iron nanoparticles: a novel magnetic resonance agent for T 1 and T2 weighted imaging," Nanotechnology, vol. 17, no. 3, pp. 640-644, 2006.

[78] M. Rahman, M. Abd-El-Barr, V. MacK et al., "Optical imaging of cervical pre-cancers with structured illumination: an integrated approach," Gynecologic Oncology, vol. 99, no. 3, supplement 1, pp. S112-S115, 2005.

[79] M. Eghtedari, A. V. Liopo, J. A. Copland, A. A. Oraevsky, and M. Motamed, "Engineering of hetero-functional gold nanorods for the in vivo molecular targeting of breast cancer cells," Nano Letters, vol. 9, no. 1, pp. 287-291, 2009. 
[80] J. C. Y. Kah, K. W. Kho, C. G. Lee et al., "Early diagnosis of oral cancer based on the surface plasmon resonance of gold nanoparticles," International Journal of Nanomedicine, vol. 2, no. 4, pp. 785-798, 2007.

[81] X. M. Qian, X. H. Peng, D. O. Ansari et al., "In vivo tumor targeting and spectroscopic detection with surface-enhanced Raman nanoparticle tags," Nature Biotechnology, vol. 26, no. 1, pp. 83-90, 2008.

[82] X. H. Huang, I. H. El-Sayed, W. Qian, and M. A. El-Sayed, "Cancer cells assemble and align gold nanorods conjugated to antibodies to produce highly enhanced, sharp, and polarized surface Raman spectra: a potential cancer diagnostic marker," Nano Letters, vol. 7, no. 6, pp. 1591-1597, 2007.

[83] A. Agarwal, S. W. Huang, M. O’Donnell et al., “Targeted gold nanorod contrast agent for prostate cancer detection by photoacoustic imaging," Journal of Applied Physics, vol. 102, no. 6, pp. 064701-064704, 2007.

[84] W. Eck, G. Craig, A. Sigdel et al., "PEGylated gold nanoparticles conjugated to monoclonal F19 antibodies as targeted labeling agents for human pancreatic carcinoma tissue," ACS Nano, vol. 2, no. 11, pp. 2263-2272, 2008.

[85] C. D. Medley, J. E. Smith, Z. Tang, Y. Wu, S. Bamrungsap, and W. Tan, "Gold nanoparticle-based colorimetric assay for the direct detection of cancerous cells," Analytical Chemistry, vol. 80, no. 4, pp. 1067-1072, 2008.

[86] W. T Lu, S. R. Arumugam, D. Senapati et al., "Multifunctional oval-shaped gold-nanoparticle-based selective detection of breast cancer cells using simple colorimetric and highly sensitive two-photon scattering assay," ACS Nano, vol. 4, no. 3, pp. 1739-1749, 2010.

[87] J. A. Viator, S. Gupta, B. S. Goldschmidt et al., "Gold nanoparticle mediated detection of prostate cancer cells using photoacoustic flowmetry with optical reflectance," Journal of Biomedical Nanotechnology, vol. 6, no. 2, pp. 187-191, 2010.

[88] A. Ambrosi, F. Airo, and A. Merkoci, "Enhanced gold nanoparticle based ELISA for a breast cancer biomarker," Analytical Chemistry, vol. 82, no. 3, pp. 1151-1156, 2010.

[89] J. H. Kang, Y. Asami, M. Murata et al., "Gold nanoparticlebased colorimetric assay for cancer diagnosis," Biosensors and Bioelectronics, vol. 25, no. 8, pp. 1869-1874, 2010.

[90] F. Zhou, L. Yuan, H. Wang, D. Li, and H. Chen, "Gold nanoparticle layer: a promising platform for ultra-sensitive cancer detection," Langmuir, vol. 27, no. 6, pp. 2155-2158, 2011.

[91] H. Chon, S. Lee, S. W. Son, C. H. Oh, and J. Choo, "Highly sensitive immunoassay of lung cancer marker carcinoembryonic antigen using surface-enhanced raman scattering of hollow gold nanospheres," Analytical Chemistry, vol. 81, no. 8, pp. 3029-3034, 2009.

[92] I. H. El-Sayed, X. Huang, and M. A. El-Sayed, "Surface plasmon resonance scattering and absorption of anti-EGFR antibody conjugated gold nanoparticles in cancer diagnostics: applications in oral cancer," Nano Letters, vol. 5, no. 5, pp. 829-834, 2005.

[93] X. G. Shi, S. Wang, S. Meshinchi et al., "Dendrimer-entrapped gold nanoparticles as a platform for cancer-cell targeting and imaging," Small, vol. 3, no. 7, pp. 1245-1252, 2007.

[94] I. C. Sun, D.-K. Eun, J. H. Na et al., "Heparin-coated gold nanopartieles for liver-specific CT imaging," Chemistry, vol. 15, no. 48, pp. 13341-13347, 2009.

[95] C. Alric, J. Taleb, G. Le Duc et al., "Gadolinium chelate coated gold nanoparticles as contrast agents for both X-ray computed tomography and magnetic resonance imaging,"
Journal of the American Chemical Society, vol. 130, no. 18, pp. 5908-5915, 2008.

[96] M. Kumagai, T. K. Sarmat, H. Cabral et al., "Enhanced in vivo magnetic resonance imaging of tumors by PEGylated ironoxide-gold core-shell nanoparticles with prolonged blood circulation properties," Macromolecular Rapid Communications, vol. 31, no. 17, pp. 1521-1528, 2010.

[97] Nasiruzzaman Sk Md, H. K. Kim, J. A. Park, Y. Chang, and T. J. Kim, "Gold nanoparticles coated with Gd-chelate as a potential CT/MRI bimodal contrast agent," Bulletin of the Korean Chemical Society, vol. 31, no. 5, pp. 1177-1181, 2010.

[98] H. He, C. Xie, and J. Ren, "Nonbleaching fluorescence of gold nanoparticles and its applications in cancer cell imaging," Analytical Chemistry, vol. 80, no. 15, pp. 5951-5957, 2008.

[99] H. Lee, K. Lee, I. K. Kim, and T. G. Park, "Fluorescent gold nanoprobe sensitive to intracellular reactive oxygen species," Advanced Functional Materials, vol. 19, no. 12, pp. 1884$1890,2009$.

[100] A. M. Coto-Garcia, E. Sotelo-Gonzalez, M. T. FernandezArguelles, R. Pereiro, J. M. Costa-Fernandez, and A. SanzMedel, "Nanoparticles as fluorescent labels for optical imaging and sensing in genomics and proteomics," Analytical and Bioanalytical Chemistry, vol. 399, no. 1, pp. 29-42, 2011.

[101] P. C. Ray, G. K. Darbha, A. Ray, J. Walker, and W. Hardy, "Gold nanoparticle based FRET for DNA detection," Plasmonics, vol. 2, no. 4, pp. 173-183, 2007.

[102] S. Lee, E. J. Cha, K. Park et al., "A near-infrared-fluorescencequenched gold-nanoparticle imaging probe for in vivo drug screening and protease activity determination," Angewandte Chemie, vol. 47, no. 15, pp. 2804-2807, 2008.

[103] C. C. You, O. R. Miranda, B. Gider et al., "Detection and identification of proteins using nanoparticle-fluorescent polymer "chemical nose" sensors," Nature Nanotechnology, vol. 2, no. 5, pp. 318-323, 2007.

[104] S. Mayilo, M. A. Kloster, M. Wunderlich et al., "Long-range fluorescence quenching by gold nanoparticles in a sandwich immunoassay for cardiac troponin T," Nano Letters, vol. 9, no. 12 , pp. 4558-4563, 2009.

[105] American Cancer Socity of research, "Cancer fact and figure," Health Policy, 2010, http://www.cancer.org/acs/groups/content/@nho/documents/document/acspc-024113.pdf.

[106] Y. E. Choi, J. W. Kwak, and J. W. Park, "Nanotechnology for early cancer detection," Sensors, vol. 10, no. 1, pp. 428-455, 2010.

[107] L. F. Cheow, S. H. Ko, S. J. Kim, K. H. Kang, and J. Han, "Increasing the sensitivity of enzyme-linked immunosorbent assay using multiplexed electrokinetic concentrator," Analytical Chemistry, vol. 82, no. 8, pp. 3383-3388, 2010.

[108] Y. Pellequer and A. Lamprecht, "Nanoscale cancer therapeutics," in Nanotherapeutics: Drug Delivery Concepts in Nanoscience, A. Lamprecht, Ed., pp. 93-124, Pan Stanford, Chicago, Ill, USA, 2009.

[109] Z. Fang, L. Soleymani, G. Pampalakis et al., "Direct profiling of cancer biomarkers in tumor tissue using a multiplexed nanostructured microelectrode integrated circuit," ACS Nano, vol. 3, no. 10, pp. 3207-3213, 2009.

[110] W. Yang, M. Yu, X. Sun, and A. T. Woolley, "Microdevices integrating affinity columns and capillary electrophoresis for multibiomarker analysis in human serum," Lab on a Chip, vol. 10, no. 19, pp. 2527-2533, 2010.

[111] P. Baptista, E. Pereira, P. Eaton et al., "Gold nanoparticles for the development of clinical diagnosis methods," Analytical and Bioanalytical Chemistry, vol. 391, no. 3, pp. 943-950, 2008. 
[112] W. Zhao, M. A. Brook, and Y. Li, "Design of gold nanoparticle-based colorimetric biosensing assays," ChemBioChem, vol. 9, no. 15, pp. 2363-2371, 2008.

[113] X. Huang, P. K. Jain, I. H. El-Sayed, and M. A. El-Sayed, "Gold nanoparticles: interesting optical properties and recent applications in cancer diagnostics and therapy," Nanomedicine, vol. 2, no. 5, pp. 681-693, 2007.

[114] A. W. H. Lin, N. A. Lewinski, J. L. West, N. J. Halas, and R. A. Drezek, "Optically tunable nanoparticle contrast agents for early cancer detection: model-based analysis of gold nanoshells," Journal of Biomedical Optics, vol. 10, no. 6, 2005.

[115] K. Lee, V. P. Drachev, and J. Irudayaraj, "DNA-gold nanoparticle reversible networks grown on cell surface marker sites: Application in diagnostics," ACS Nano, vol. 5, no. 3, pp. 2109-2117, 2011.

[116] S. X. Tang and I. Hewlett, "Nanoparticle-based immunoassays for sensitive and early detection of HIV-1 capsid (p24) antigen," The Journal of Infectious Diseases, vol. 201, supplement 1, pp. S59-S64, 2010.

[117] J. F. Tang, L. Zhou, W. Gao, X. Cao, and Y. Wang, "Visual DNA microarrays for simultaneous detection of human immunodeficiency virus type- 1 and Treponema pallidum coupled with multiplex asymmetric polymerase chain reaction," Diagnostic Microbiology and Infectious Disease, vol. 65, no. 4, pp. 372-378, 2009.

[118] M.-C. Bowman, T. E. Ballard, C. J. Ackerson, D. L. Feldheim, D. M. Margolis, and C. Melander, "Inhibition of HIV fusion with multivalent gold nanoparticles," Journal of the American Chemical Society, vol. 130, no. 22, pp. 6896-6897, 2008.

[119] P. Di Gianvincenzo, M. Marradi, O. M. Martinez-Avila, L. M. Bedoya, J. Alcami, and S. Penades, "Gold nanoparticles capped with sulfate-ended ligands as anti-HIV agents," Bioorganic and Medicinal Chemistry Letters, vol. 20, no. 9, pp. 2718-2721, 2010.

[120] K. A. Mahmoud, S. Hrapovic, and J. H. T. Luong, "Picomolar detection of protease using peptide/single walled carbon nanotube/gold nanoparticle-modified electrode," ACS Nano, vol. 2, no. 5, pp. 1051-1057, 2008.

[121] K. A. Mahmoud and J. H. T. Luong, "Impedance method for detecting HIV-1 protease and screening for its inhibitors using ferrocene-peptide conjugate/Au nanoparticle/singlewalled carbon nanotube modified electrode," Analytical Chemistry, vol. 80, no. 18, pp. 7056-7062, 2008.

[122] G. K. Darbha, U. S. Rai, A. K. Singh, and P. C. Ray, "Goldnanorod-based sensing of sequence specific HIV-1 virus DNA by using hyper-rayleigh scattering spectroscopy," Chemistry, vol. 14, no. 13, pp. 3896-3903, 2008.

[123] S. B. Lee, "Focus on nanoparticles for cancer diagnosis and therapeutics," Nanomedicine, vol. 2, no. 5, pp. 647-648, 2007.

[124] M. Y. Sha, H. Xu, S. G. Penn, and R. Cromer, "SERS nanoparticles: a new optical detection modality for cancer diagnosis," Nanomedicine, vol. 2, no. 5, pp. 725-734, 2007.

[125] S. Spisak and A. Guttman, "Biomedical applications of protein microarrays," Current Medicinal Chemistry, vol. 16, no. 22, pp. 2806-2815, 2009. 

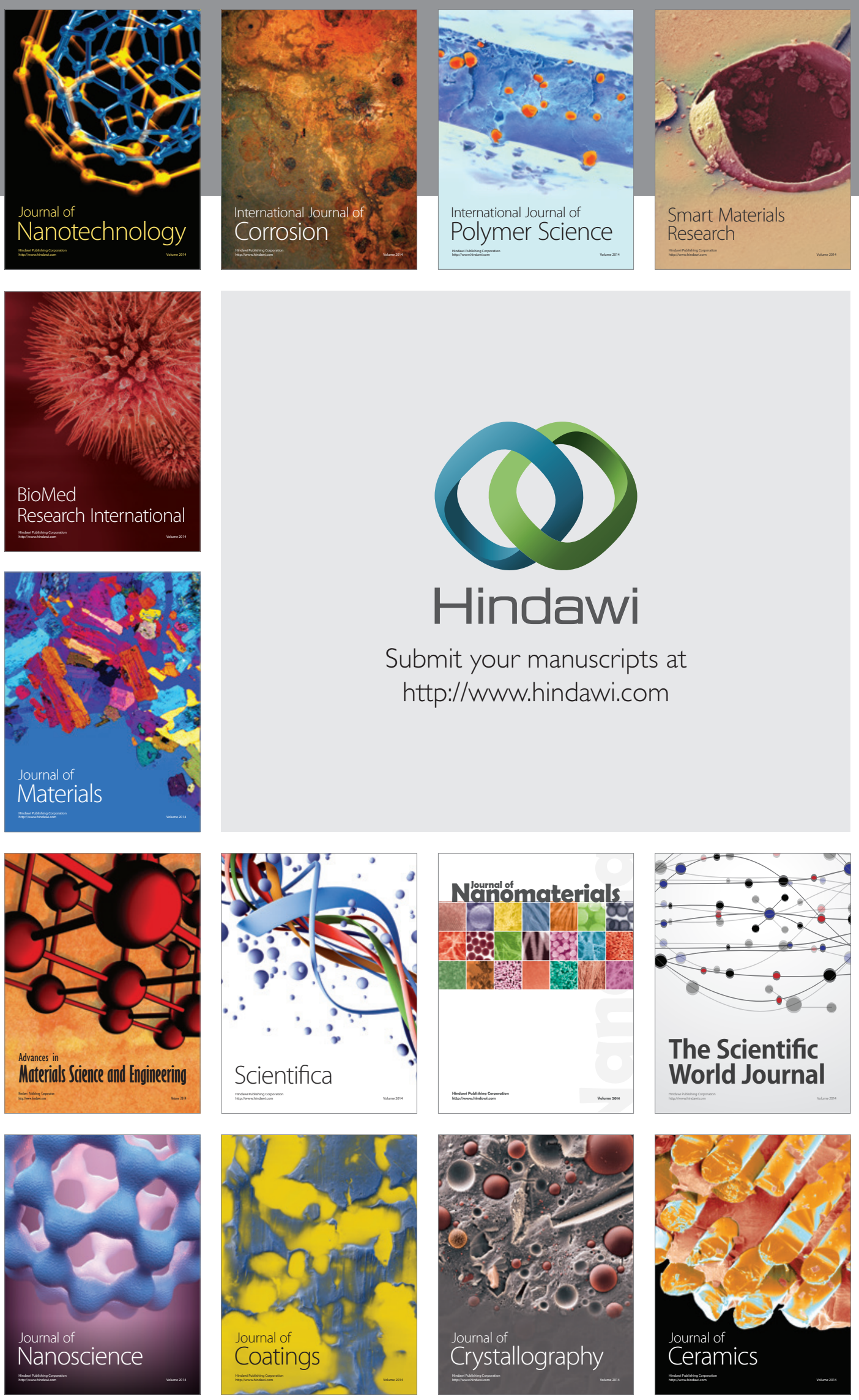

The Scientific World Journal

Submit your manuscripts at

http://www.hindawi.com

\section{World Journal}

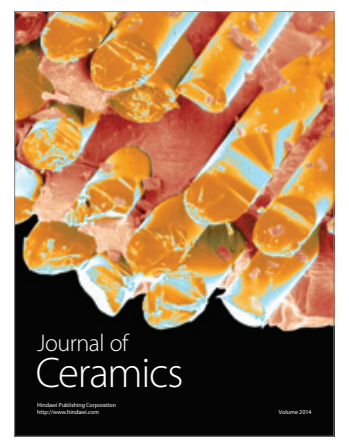

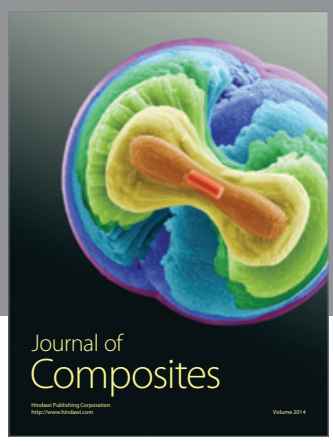
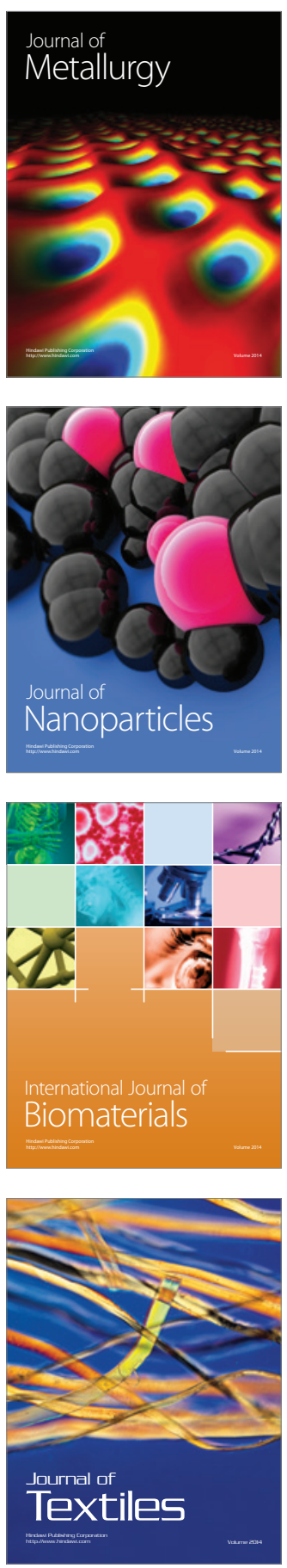